\title{
3 Zur Theorie der Cinematic Metaphor
}

\subsection{Einleitung}

Theoretisch präzisieren lässt sich der Terminus ,multidimensionale Erfahrungsgestalt‘ im Begriff der Ausdrucksbewegung. Scheint es doch einigermaßen evident, dass die grundlegende Verknüpfung des Intervalls kooperativer Interaktion ihren Ausgang nicht in sprachlichen, sondern gestischen Ausdrucksformen körperlicher Interaktion nimmt: nämlich in der Wahrnehmung motorischer Abläufe des anderen Körpers und der Fähigkeit, diese Abläufe perspektivisch auf den Aktionsradius des eigenen Körpers zu beziehen. Die Wahrnehmung der Aktion des Anderen kann so zur initiierenden Expression werden, die das Intervall von (Re-)Perzeption, Aktion und motorischer Umsetzung in Gang setzt. ${ }^{1}$,Ausdrucksbewegung' meint genau solche initiierenden Expressionen, seien diese nun lautlich oder motorisch vollzogen. Sie sind zwar intentional gerichtet; und doch haben sie per se keinen zeichenhaften Charakter. Man kann sie sehr wohl (motorisch oder lautlich ausgeführte) Gesten nennen; muss dann aber strikt zwischen gestischen Zeichen und gestischen Ausdrucksbewegungen unterscheiden, die unmittelbar bedeuten wollen. Im Letzten bezeichnet die Ausdrucksbewegung nichts anderes als das Verhältnis zwischen affizierendem und affiziertem Körper. ${ }^{2}$

In unserer Forschung begegnete uns das Konzept der Ausdruckbewegung zunächst und vor allem als filmtheoretischer Topos der künstlerischen Avantgarden des frühen zwanzigsten Jahrhunderts. Es bezog sich auf die Bewegung der kinematografischen Bewegtbilder, in der man die spezifische Expressivität des neuen Mediums zu fassen suchte. ${ }^{3}$

1 Vgl. u. a. Katja Liebal/Simone Pika/Michael Tomasello: Social Communication in Siamangs (Symphalangus Syndactylus): Use of Gestures and Facial Expressions, in: Primates 45 (1), 2004, S. 41-57; Simone Pika/Katja Liebal/Michael Tomasello: Gestural Communication in Subadult Bonobos (Pan Paniscus): Repertoire and Use, in: American Journal of Primatology 65 (1), 2005, S. 39-61; Katja Liebal/Simone Pika/Michael Tomasello: Gestural Communication of Orangutans (Pongo Pygmaeus), in: Gesture 6 (1), 2006, S.1-38.

2 Vgl. Massumi: Parables for the Virtual; Massumi: Ontomacht.

3 Vgl. Sarah Greifenstein/Hermann Kappelhoff: Audiovisual Metaphors: Embodied Meaning and Processes of Fictionalization, in: Embodied Metaphors in Film, Television, and Video Games, hrsg. v. Kathrin Fahlenbrach, New York 2016, S. 183-201; Kappelhoff/Müller: Embodied Meaning Construction. Wir haben dieses Konzept in verschiedenen Kontexten ausgearbeitet. Entscheidend war diesbezüglich unter anderem das im Rahmen des Exzellenzclusters „Languages of Emotion“ durchgeführte Projekt „Affektmobilisierung und mediale Kriegsinszenierung“ (Lei-

Ә Open Access. (c) 2018 Hermann Kappelhoff, publiziert von De Gruyter. (c) BY-NC-ND Dieses Werk ist lizenziert unter der Creative Commons Attribution-NonCommercial-NoDerivatives 4.0 Lizenz. https://doi.org/10.1515/9783110614855-004 
Im dritten Teil des Buches möchte ich mich deshalb vorwiegend auf den primären Gegenstand unserer Forschung im Kolleg Cinepoetics beziehen, nämlich den Film und das kinematografische Bewegtbild. Ich halte zwar auch weiterhin an der grundlegenden Ausrichtung meiner Argumente am audiovisuellen Bewegtbild fest; sehe aber gerade mit Blick auf die phänomenologische Theorie des Bewegungsbildes die Notwendigkeit präziser terminologischer Differenzierungen, die den unterschiedlichen medientechnischen Dispositiven Rechnung tragen. Sie in ein und demselben Argumentationszug einzuholen, würde die Darlegung unnötig komplizieren. Deshalb ist im Folgenden von ,kinematografischen Bildern' und ,Zuschauern“ die Rede, unbenommen des Anspruchs, dass die entwickelten Argumente und Thesen auf alle Formen audiovisueller Bilder zu beziehen sind.

So unterschiedliche Poetiken wie die des Weimarer Autorenkinos, der französischen Filmavantgarde und der russischen Montageschule teilten die Vorstellung, dass es dem kinematografischen Bild möglich sei, eine gänzlich neue Dimension von Bewegung anschaulich zu entfalten: eine Bewegung, die quer zur Scheidung von Raum und Zeit verläuft ${ }^{4}$ und in der die dynamischen Wechsel der Montage mit der Intensität des Mienenspiels einer Schauspielerin, die parallel laufenden Aktionslinien dahin jagender Verfolger mit dem im Abendwind sich blähenden Segel, der Sturmlauf einer Horde von Soldaten mit den in schillernden Lichtreflexen sich drehenden Nebeln als Bewegung des filmischen Bildes sich zu einem Ausdrucksgefüge verbinden.

„Eine Bewegung läuft an, verläßt ihre natürliche Bahn, wird von einer anderen aufgefangen, weiter geleitet, wieder gekrümmt und zerbrochen. Dazwischen spielt, aufbauend, trennend, betonend, zerstörend der Zauber des Lichts,

\footnotetext{
tung: Hermann Kappelhoff; ProjektmitarbeiterInnen: Jan-Hendrik Bakels, Hye-Jeung Chung, David Gaertner, Sarah Greifenstein, Matthias Grotkopp, Michael Lück, Christian Pischel, Franziska Seewald, Anna Steininger) und um das von der DFG geförderte Nachfolgeprojekt „Inszenierungen des Bildes vom Krieg als Medialität des Gemeinschaftserlebens“ (Leitung: Hermann Kappelhoff; ProjektmitarbeiterInnen: Tobias Haupts, David Gaertner, Danny Gronmaier, Cilli Pogodda, Eileen Rositzka; assoziierte Mitarbeiter: Jan-Hendrik Bakels, Matthias Grotkopp, Christian Pischel).

4 „Bewegung liegt allem Werden zugrunde. In Lessings Laokoon, an dem wir einmal jugendliche Denkversuche verzettelten, wird viel Wesens aus dem Unterschied von zeitlicher zu räumlicher Kunst gemacht. Und bei genauerem Zusehen ist's doch nur gelehrter Wahn. Denn auch der Raum ist ein zeitlicher Begriff.“ Paul Klee: Schöpferische Konfession, in: Kunst-Lehre. Aufsätze, Vorträge, Rezensionen und Beiträge zur bildnerischen Formlehre, hrsg. v. Günther Regel, Leipzig 1991, S. 60-66, hier S. 62.
} 
die Entfesselung von Helle und Schwärze. “5 So beschreibt Rudolf Kurtz 1926 mit Blick auf das Weimarer Autorenkino eine Bewegung, die den filmischen Bildern selbst eignet.

Ob die Poetik des expressionistischen Films von Rudolf Kurz oder die Idee einer vierten Dimension des filmischen Bildes bei Sergej Eisenstein, ob Béla Balázs’ Auffassung vom filmischen Bild als Gefühlsakkord ${ }^{6}$ oder Hugo Münsterbergs Wahrnehmungspsychologie des Films ${ }^{7}$ - immer wird die Bewegung des kinematografischen Bewegtbildes selbst als das Spezifikum des neuen Mediums ins Zentrum gerückt. Bewegung meint dann freilich gerade nicht die Verlagerung von Objekten in einem gegebenen homogenen Raum, sondern die Dauer der Wandlung des Ganzen der filmischen Welt, mit der der Raum zur Funktionale der Zeit wird. ${ }^{8}$

Vor allem Münsterberg entwickelte daraus ein rezeptionsästhetisches Modell der wechselseitigen Verzahnung zwischen der Rhythmik der sich entfaltenden Bewegung des kinematografischen Bildes und der affektiven Dynamik des Prozesses filmischer Rezeption. Man könnte es ein bewegungstheoretisches Modell von Empathie nennen, dessen Zentrum die Ausdrucksbewegung des kinematografischen Bewegtbilds selber ist. Sehr viel wirkmächtiger hat Eisenstein diese Vorstellung massenpsychologisch ausbuchstabiert und die Ausdrucksbewegung kinematografischer Montagen als Movens interaffektiver Verschränkung menschlicher und nicht-menschlicher Körper beschrieben.

Béla Balázs wiederum hat das Wechselverhältnis der Bewegung des filmischen Bildes und der affektiven Bewegtheit der Zuschauer am Paradigma der Wahrnehmung des Gesichts in Großaufnahme als Ausdrucksbewegung der Mimik analysiert:

Wie die Melodie zur Zeit, so verhält sich die Physiognomie zum Raum. Die Ausdrucksmuskeln des Gesichts liegen wohl räumlich nebeneinander. Aber ihre Beziehung macht den Ausdruck. Diese Beziehung hat keine Ausdehnung und keine Richtung im Raum. Sowenig wie eben Gefühle und Gedanken und sowenig wie Vorstellungen und Assoziationen. Diese sind auch bildhaft und doch raumlos. ${ }^{9}$

5 Rudolf Kurtz: Expressionismus und Film. Unveränd., fotomechan. NachDr. d. Orig.-Ausgabe, Zürich 1965, S. 123.

6 Vgl. Balázs: Der sichtbare Mensch oder die Kultur des Films; Eisenstein: Das dynamische Quadrat, in: ders.: Das dynamische Quadrat. Schriften zum Film, hrsg. v. Oksana Bulgakowa, Dietmar Hochmuth, Köln 1988, S.157-176; Kurtz: Expressionismus und Film.

7 Vgl. Münsterberg: Das Lichtspiel, S. $41 \mathrm{ff}$.

8 Vgl. Panofsky: Stil und Medium im Film \& Die ideologischen Vorläufer des Rolls-Royce-Kühlers, S. 23.

9 Béla Balázs: Der Geist des Films, Frankfurt/M. 2001, S. 17. 
In Balázs’ Beschreibungen wird das kinematografische Bewegtbild in der Verschränkung von mimischer Ausdrucksbewegung des Gesichts, der Bewegung des filmischen Bildes in der Dauer seiner zeitlichen Entfaltung und der Bewegtheit der Zuschauer - einer Empfindungsbewegung, die als Gefühl am eigenen Leibe wahrgenommen wird - unmittelbar als Einheit eines filmischen Bewegungsbildes greifbar.

In irgendeinem Film schaut Asta Nielsen zum Fenster hinaus und sieht jemanden kommen. Ein tödlicher Schreck, ein versteinertes Entsetzen erscheint auf ihrem Gesicht. Doch sie erkennt allmählich, daß sie schlecht gesehen hat und der sich Nähernde kein Unglück, sondern im Gegenteil größtes Glück für sie bedeutet. Und aus dem Ausdruck des Entsetzens wird langsam, allmählich durch die ganze Skala von zagem Zweifeln, banger Hoffnung, vorsichtiger Freude hindurch die Ekstase des Glücks. Wir sehen dieses Gesicht etwa zwanzig Meter lang in Großaufnahme. Wir sehen jeden Zug um Augen und Mund sich einzeln lösen, lockern und langsam verändern. Minutenlang sehen wir die organische Entwicklungsgeschichte ihrer Gefühle und nichts weiter. Ja, das ist eine Geschichte, die wir sehen. Das ist die spezielle Filmlyrik, die eigentlich eine Epik der Empfindungen ist. ${ }^{10}$

Zwanzig Meter, das meint die Dauer eines kinematografischen Bewegtbildes, das sich für den Zuschauer als ,Entwicklungsgeschichte seines Empfindens vollzieht‘; das meint die Zeit, in der die Wandlungen des Kamerabildes den Prozess des sich entfaltenden Wahrnehmungsempfindens auf Seiten der Zuschauer strukturieren und unmittelbar auf die Zeit der Verwandlung des Gesichts beziehen - „Wir sehen [...]. Wir sehen [...]. Minutenlang sehen wir [...]“ -, während die Dauer des Kamerabildes das eine wie das andere, die mimische Ausdrucksbewegung und den perzeptiven Prozess, zu einer einzigen Bewegungsfiguration, einem ,Gefühlsakkord' zusammenfasst. Erst in der verzweigten Temporalität der Poiesis des Filme-Sehens wird die mimische Bewegung in der Dauer des kinematografischen Bewegtbildes zur Ganzheit eines filmischen Bewegungsbildes.

Ich erwähne Balázs auch deshalb ausführlich, weil seine Poetik des kinematografischen Bildes das Bewegungsbild tatsächlich erst aus der Interaktion zwischen Leinwandbild und Zuschauerkörpern hervorgehen sieht; seine Überlegungen beleuchten auch schlaglichtartig die diskursive Konstellation, der sich die Idee der filmischen Bewegung als Ausdrucksbewegung verdankt.

10 Balázs: Der sichtbare Mensch oder die Kultur des Films, S. 44-45. 


\subsection{Die Ausdrucksbewegung}

Denn im Hintergrund steht nicht nur Georg Simmel - Balázs akademischer Lehrer, der bereits 1901 in seinem Aufsatz „Über die ästhetische Bedeutung des Gesichts“ ein Konzept der Ausdrucksbewegung skizzierte, in dem vieles vorgezeichnet ist, was für die klassische Filmtheorie bedeutsam wird. Vielmehr kann Balázs auf einen Begriff der Ausdrucksbewegung zurückgreifen, der in der ersten Hälfte des letzten Jahrhunderts gleichermaßen in der Psychologie, der Sprachwissenschaft, der Kunstwissenschaft und der philosophischen Ästhetik von zentraler Bedeutung war.

So schreibt Wilhelm Wundt:

Die psychophysischen Lebensäußerungen, denen die Sprache als eine besondere, eigenartig entwickelte Form zugezählt werden kann, bezeichnen wir ihrem allgemeinen Begriffe nach als Ausdrucksbewegungen. Jede Sprache besteht in Lautäußerungen oder in andern sinnlich wahrnehmbaren Zeichen, die, durch die Muskelwirkungen hervorgebracht, innere Zustände, Vorstellungen, Gefühle, Affekte, nach außen kundgeben. ${ }^{11}$

Die klassischen filmpoetologischen Entwürfe sind nämlich selbst in einem Diskurs zu situieren, in dem die moderne Psychologie und Linguistik sich noch einmal eng mit der philosophischen Ästhetik und der Kunsttheorie in der Frage nach dem physiognomischen Denken verbanden. Das sind zum einen psychologische und anthropologische Konzepte, wie sie im ersten Drittel des letzten Jahrhunderts von Wilhelm Wundt, Karl Bühler und Helmuth Plessner formuliert wurden. Zum anderen sind es ästhetisch-philosophische Modelle, wie sie etwa Georg Simmel und Konrad Fiedler entwickelten. ${ }^{12}$

11 Wilhelm Wundt: Völkerpsychologie. Eine Untersuchung der Entwicklungsgesetze von Sprache, Mythus und Sitte. Erster Band. Die Sprache, Leipzig 1911, S. 43.

12 Vgl. Karl Bühler: Ausdruckstheorie. Das System an der Geschichte aufgezeigt, Jena 1933; Helmuth Plessner: Die Deutung des mimischen Ausdrucks. Ein Beitrag zur Lehre vom Bewußtsein des anderen Ichs, in: ders.: Gesammelte Schriften VII. Ausdruck und menschliche Natur, Frankfurt/M. 1982, S. 67-130; Wilhelm Wundt: Grundzüge der physiologischen Psychologie, Bd.2, Leipzig 1880, S. 418 ff; Wilhelm Wundt: Grundriss der Psychologie, Leipzig 1896; Konrad Fiedler: Moderner Naturalismus und künstlerische Wahrheit, in: ders.: Schriften zur Kunst I, München 1991, S. 82-110; Konrad Fiedler: Über den Ursprung der künstlerischen Tätigkeit, in: ders.: Schriften zur Kunst I, München 1991, S. 112-220; Georg Simmel: Aesthetik des Porträts, in: ders.: Aufsätze und Abhandlungen 1901-1908 (Bd. I), Frankfurt/M. 1995, S. 321-332; Georg Simmel: Die ästhetische Bedeutung des Gesichts, in: ders.: Aufsätze und Abhandlungen 1901-1908 (Bd. I), Frankfurt/M. 1995, S. 36-42. 


\section{Ein gestisches Bewegungsbild}

Damit ist grob eine wissenschaftsgeschichtliche Konstellation umrissen, auf die sich noch die gegenwärtige Filmtheorie bezieht, wenn sie von der affizierenden Kraft filmischer Bilder spricht. Im Horizont dieser diskursiven Konstellation entwickelt der Philosoph Helmuth Plessner ein modernes Konzept der Ausdrucksbewegung, das er, fernab aller film- oder medientheoretischen Überlegungen, im Begriff des „Bewegungsbildes“13 $\mathrm{zu}$ fassen sucht.

Die Ausdrucksbewegung sei eine motorische Aktion, die nicht von einem intentional verstandenen Handlungsziel her betrachtet wird, sondern ein Bild des Ganzen der Interaktion eines Organismus und seiner Umwelt bezeichne. ${ }^{14}$ Sie hebt sich gleichsam als das figurative Verhaltensmuster von der Aktion, als eine Art gestische Formschicht von der organischen Bewegung ab: ${ }^{15}$

Wo immer im Reich des Organischen Bewegungen erscheinen, verlaufen sie nach einheitlichem Rhythmus, zeigen sie eine, wohl auch experimentell nachweisbare, dynamische Gestalt. Sie rollen nicht stückhaft ab, als ob ihre Phasenfolge aus einzelnen Elementen assoziiert worden wäre, bilden kein Zeitmosaik, sondern eine gewisse Ganzheit ist vorgegeben, innerhalb deren die einzelnen Bewegungskurven variierbar sind..$^{16}$

Während die Aktion in der Zeit sukzessive abläuft und entsprechend gegliedert und analysiert werden kann, bezeichnet die Ausdrucksbewegung die Zeit der Entfaltung des dynamischen Austauschverhältnisses von Organismus und Umwelt als ein Bildganzes: Die Ausdrucksbewegung dauert, statt fortzuschreiten; sie ist die zeitliche Figuration der sich unter dem Einfluss einer konkreten Aktion verändernden Umwelt. Die Figur des Vorgangs dieser Veränderung nennt Plessner „Bewegungsbild“. ${ }^{17}$

Diese Ganzheiten gehören zum Organismus durch sein Verhältnis zur Umwelt, seine Morphologie, seine artspezifischen Instinkte als motorische Kategorien [...]. Infolgedessen sind die Bewegungsgestalten bildhaft, wenn auch über eine gewisse Zeitdauer erstreckt, dem Beobachter gegenwärtig. [...] Greifen, Fliehen, Abwehren, Suchen, aber auch schon die

13 Vgl. Plessner: Die Deutung des mimischen Ausdrucks, S. $67 \mathrm{ff}$.

14 „Im Ausdruck wird ein Ganzes manifest und in dieser Manifestation ruht der lebendige Träger des Ausdrucks.“ Plessner, S. 94.

15 Plessner, S. 82.

16 Plessner, S. $77 \mathrm{f}$.

17 Ungeachtet der grundlegenden Differenzen zwischen einer anthropologischen und einer konstruktivistischen Denkweise, lässt sich Plessners Verständnis durchaus mit dem filmtheoretischen Begriff des Bewegungs-Bilds bei Deleuze vergleichen. Beide Begriffsbildungen stützen sich auf dieselben philosophischen Grundlagen, nämlich auf Henri Bergson. 
„affektlosen“ Formen wie Gehen, Fliegen, Schwimmen [...] stellen solche Bewegungsbilder dar. $^{18}$

Das Bewegungsbild ist also durch einen spezifischen Wahrnehmungsmodus bestimmt. Motorische Aktionen werden dann zu Bewegungsbildern, wenn sie nicht in der Logik intentionaler Handlungsziele analysiert, sondern als Ausdruck des Verhaltens- oder Antriebstypus eines agierenden Körpers wahrgenommen werden. In diesem Sinne bezeichnet die Ausdrucksbewegung die temporale Formgestalt einer motorischen Aktion, die sich im Wahrnehmungsempfinden eines leibhaften Gegenübers als affektive Resonanz ausprägt. Es ist eine bestimmte Verhaltensschicht, die sich dergestalt als dynamisches Formmuster eines Bewegungsbildes kundtut und der eine spezifische Wahrnehmungssensibilität für solche Formmuster antwortet.

Daß die Katze mir davonläuft, läßt sich auch objektiv in bloßen Bewegungen darstellen: daß sie mich ängstlich flieht, ist mir überdies in diesen Bewegungen als einheitlicher Charakter mitgegeben. Daß der Hund an mir emporspringt, ist objektiv konstatierbar; daß er mich freudig begrüßt, ist mir in seinem Gebaren als Richtungsform deutlich. ${ }^{19}$

Die Ausdrucksbewegung vollzieht sich als Spannungsgefüge zwischen dem Wahrnehmen eines motorischen Bewegungsmusters eines Körpers und der Wahrnehmung des gleichen Musters als Bewegungsbild, das in seiner Gänze zur Expression der intentionalen Anspannung dieses anderen Körpers wird.

Plessner spricht von einer unmittelbaren Wahrnehmung des Psychischen, einem Gewahrwerden ohne Schließen, einem unmittelbaren Innewerden der motorischen Aktion als Ausdruck der die Aktion bestimmenden Affekte. ${ }^{20} \mathrm{Er}$ legt nahe, dass dieser Wahrnehmungsmodus sich auf dem Umstand gründet, dass das ,Sinnlich-Bildhafte' der Bewegung einer Form-Funktionsgesetzlichkeit untersteht, die gleichermaßen dem Psychischen wie dem Physischen angehört. Er nennt diese geteilte Formebene die Sphäre des Verhaltens. ${ }^{21}$ Dann wäre die Ausdrucksbewegung die grundlegende Relation der Interaktion kooperierend aufeinander bezogener Körper.

Die Ausdrucksbewegung betrifft letztlich einen Wahrnehmungsmodus, den man als grundlegende Form empathischen Verhaltens verstehen kann. Plessner konzipiert diesen Wahrnehmungsmodus wie die Wahrnehmung eines Kippbil-

18 Plessner: Die Deutung des mimischen Ausdrucks, S. 78.

19 Plessner, S. 82.

20 Plessner, S. $118 \mathrm{f}$.

21 Plessner, S. 129. 
des: Man sieht entweder die motorische Bewegung eines anderen Körpers als objektive Gegebenheit der umgebenden Welt. Oder man sieht ein Bewegungsbild, das ,unmittelbar' als Expression intentionaler Gerichtetheit erfahren wird; in dem das wahrnehmende ,Ich' sich selbst gemeint, angesprochen, in seiner eigenen Leiblichkeit affiziert erlebt - eine interaffektive Verschränkung, die sich zwanglos auf das oben schematisch skizzierte Intervall kooperativer Interaktion beziehen lässt. ${ }^{22}$

Doch lässt sich das Kippen des Bildes eben auch als reflexive Wendung verstehen, mit der das Feld einer gegebenen Interaktion als multidimensionale Erfahrungsgestalt erfasst wird. Mit Blick auf unsere Forschung zur Poetologie audiovisueller Bilder wurde der Begriff der Ausdrucksbewegung von vornherein als ein medienästhetisches Verfahren konzipiert und untersucht. Dabei wurde zum einen versucht, das Konzept kulturhistorisch als eine ästhetische Praxis affektiver Mobilisierung zu verorten, die darauf gerichtet ist, Gefühle und Selbstgefühle eines anonymen Publikums zu erzeugen und zu modellieren. Die Poetik der Ausdrucksbewegung betrifft so gesehen grundlegende mediale Darstellungspraktiken westlicher Unterhaltungskultur, in ihren diversen melodramatischen Spielarten (die Bühne, das Schauspiel, der Tanz, der Film). ${ }^{23}$ Aufbauend auf eine solche kulturgeschichtliche Perspektive haben wir das Konzept der Ausdrucksbewegung als analytische Kategorie moderner Affektpoetiken (Hollywood, Kriegsfilm und Kriegspropaganda $)^{24}$ entwickelt, die auf die affektive Responsivität eines

22 Vgl. hierzu die Ausführungen von Shaun Gallagher zum Konzept der embodied social cognition: „On the embodied view of social cognition, the mind of the other person is not something that is hidden away and inaccessible. In perceiving the actions and expressive movements of the other person in the interactive contexts of the surrounding world, one already grasps their meaning; no inference to a hidden set of mental states (beliefs, desires, etc.) is necessary. When I see the other's action or gesture, I see (I immediately perceive) the meaning in the action or gesture; and when I am in a process of interacting with the other, my own actions and reactions help to constitute that meaning." Shaun Gallagher: Understanding others: Embodied social cognition, in: Elsevier Handbook of Embodied Cognitive Science - Communication, hrsg.v.a.C. Garzón, London 2008, S. 439-452, hier S. 449.

23 Vgl. Kappelhoff: Matrix der Gefühle.

24 Vgl. Bakels: Audiovisuelle Rhythmen; Sarah Greifenstein: Tempi der Bewegung - Modi des Gefühls. Expressivität, heitere Affekte und die Screwball Comedy, Berlin/Boston 2019 (in Vorbereitung); Matthias Grotkopp: Filmische Poetiken der Schuld. Die audiovisuelle Anklage der Sinne als Modalität des Gemeinschaftsempfindens, Berlin/Boston 2017; David Gaertner: Tickets to War. Demokratie, Propaganda und Kino in den USA von 1939-1945, unveröffentlichte Dissertation, FU Berlin 2017; Cilli Pogodda: Medientechnologie und Affekt in den Inszenierungen des Irakkrieges, Unveröffentlichtes Dissertationsmanuskript, FU Berlin 2018; Eileen Rositzka: Cinematic Corpographies. Re-Mapping the War Film through the Body, Berlin/Boston 2018. 
anonymen Publikums, auf eine kollektive Subjektivität gerichtet ist, die es zu aktivieren und $\mathrm{zu}$ gestalten gilt. ${ }^{25}$

In dieser Perspektive folgt die Idee der Ausdrucksbewegung gerade nicht der individualpsychologischen Vorstellung einer subjektiven Innerlichkeit, die sich in der äußeren Erscheinung kundtut; vielmehr erscheint sie umgekehrt als ästhetisches Verfahren einer medialen Praxis, die ein Gefühl für die eigene Innerlichkeit, einen Subjektivierungseffekt hervorzurufen sucht, der in sich bereits intersubjektiv und medial strukturiert ist.

\section{Ausdrucksbewegung und „image schema“}

So verstanden lässt sich das Konzept der Ausdrucksbewegung - Christina Schmitt hat das prägnant herausgearbeitet - als kulturtheoretisches Pendant zum image schema durchbuchstabieren. ${ }^{26}$

Beide Konzepte suchen im Begriff der Bewegung Selbsterfahrungsmuster zurückzubinden an je spezifische Ausformungen der Raum-Zeit-Korrelation. Doch während das image schema dabei von einem System fixer Grundfigurationen ausgeht, zielt die Ausdrucksbewegung auf die Variabilität und Veränderbarkeit aller Raum-Zeit-Konfigurationen. Und während sich das image schema auf ein feststehendes Raum-Zeit-Verhältnis bezieht (ein homogener, festgelegter Raum, in dem die Bewegung zum Maßstab vergehender Zeit wird), sucht die Ausdrucksbewegung die permanente Ausdifferenzierung immer neuer Raum-Zeit-Konstrukte zu beschreiben. Das image schema fasst Bewegung als Verlagerung von Objekten im Raum - die Ausdrucksbewegung die dynamische Veränderung der Bewegungsqualitäten selbst; das image schema begreift Bewegung als Funktion des gegebenen Raum-Zeit-Verhältnisses - die Ausdrucksbewegung bringt spezifische Korrelationen von Zeit, Raum und Kraft hervor; das image schema betrifft ein generierendes System der Sinnproduktion - die Ausdrucksbewegung das Ereignis des Sinns als einen kontinuierlichen Entfaltungsprozess der sinnlich-perzeptiven Qualitäten eines Bewegungsbildes. ${ }^{27}$

Während das image schema ,schematische Strukturmuster sensomotorischer Vorgänge“ sich bewegender Körper zu fassen sucht, die als universelles Gerüst

25 Hauke Lehmann: Affektpoetiken des New Hollywood. Suspense, Paranoia und Melancholie, Berlin/Boston 2016.

26 Vgl. Schmitt: Wahrnehmen, fühlen, verstehen, S. 87-142, hier insbesondere S. 103-108.

27 Schmitt führt hier die höchst instruierende Liste amodaler Qualitäten an, die Daniel Stern zusammengestellt hat. Vgl. Schmitt, S. 103. 
menschlicher Wahrnehmung gelten, zielt das Konzept der Ausdrucksbewegung auf die sinnlichen Oberflächen medial in-Szene-gesetzter Wahrnehmungsereignisse. Während das image schema die basale Erfahrungsform des Sich-als-lebendiger-Körper-im-Raum-Bewegens als apriorische Gegebenheit systematisiert und auf jedwede Form von Erfahrungen des ,Sinn-Machens‘ bezieht, soll mit der Ausdrucksbewegung gerade die unendliche Variation immer neu sich bildender Raum-Zeit-Figurationen als Bewegungsbilder beschrieben werden.

Darüber hinaus sind image schemas auf sensomotorische Strukturen der Interaktion eines solitären Systems (d.i. ein für sich bestehender autonomer Organismus) mit einer gegebenen Umwelt bezogen. Mit der Ausdrucksbewegung ist die Interaktionsdynamik variabler Akteur/Medien/Zeichen-Konstellationen auf den Horizont gemeinschaftlich geteilter Weltwahrnehmung bezogen.

Endlich bezieht sich das image schema auf eine apriorisch gesetzte, d.h. transzendentale Matrix von Erfahrungen, denen selbst keine Erfahrung entspricht; einen Übergang zwischen beiden kann es nur geben, wenn man die Taxonomie der image schemas als ein generatives System universaler Tiefensemantik voraussetzt, ${ }^{28} \mathrm{zu}$ dem sich alle Erfahrung als phänotypische Variation verhält. Die Ausdrucksbewegung hingegen meint einen Schematismus, der das Kontinuum von Sinnesempfindung und Sinnkonstruktion als Ereignis des SichWahrnehmbar-Machens von Bewegungsfigurationen von der Gegenwärtigkeit der (medialen) Rezeption her methodisch zu beschreiben sucht. Ihr korrelieren variable Bildräume, in denen Bewegung die dynamische Veränderung der RaumZeit-Konfiguration selbst bezeichnet - und audiovisuelle Raum-Zeit-Figurationen, die selbst noch eine Funktion dieser Bewegung sind. ${ }^{29}$

\section{Die Einheit der Erfahrung}

Tatsächlich lassen sich audiovisuelle Bilder in ihrer Gänze sehr viel präziser als ein Netz von perzeptiven, affektiven und konzeptuellen Verstrebungen beschreiben, wenn man der wahrnehmbaren Oberflächenstruktur ihrer medialen Erscheinungsweisen folgt. Dann nämlich lassen sich die audiovisuellen Bildräume selbst als multidimensionale Erfahrungsgestalten fassen, die unmittelbar die Basis sinn-

28 Wenn in der Rezeption von Johnsons Theorie image schemas mit patterns of feeling gleichgesetzt werden, stellt das einen logisch nicht zu begründenden Kurzschluss dar. Vgl. Christina Schmitt, S. 104.

29 Auch dies ein Gedanke, der bereits in der frühen Filmtheorie formuliert wurde. Vgl. Panofsky: Stil und Medium im Film \& Die ideologischen Vorläufer des Rolls-Royce-Kühlers, S. $22 \mathrm{ff}$. 
hafter metaphorischer Konfigurationen darstellen. Die analytische Skizze von REAR WINDOW mag davon einen Eindruck vermittelt haben.

Filmische Bewegungsbilder fungieren in dieser Perspektive als ein ad hoc sich formierender common ground geteilter Erfahrung, ein allen Zuschauern gleichförmig zugängliches - weil automatisch projiziertes ${ }^{30}$ - Wahrnehmungserleben, auf das sich die metaphorische Konstruktion stützen kann. Sie sind per se als Wechselspiel multidimensionaler Erfahrungsgestalten zu begreifen, die ein raumzeitliches Aktionsfeld beschreiben, das durch die perspektivische Verortung aufeinander sich abstimmender Körper und deren intentionale Ausrichtung auf eine Objektwelt strukturiert ist. Der gemeinschaftlich geteilte Grund der Sinnkonstruktion ist also nicht im Rückgang auf apriorisch gegebene konzeptuelle Metaphern zu suchen, die im Bild repräsentiert werden, sondern unmittelbar in dem Netz von Affekten, Perzepten und Konzepten, das zwischen audiovisueller Bewegungsbildkomposition und Zuschauerkörpern entsteht. Die audiovisuelle Metapher ist gleichsam eine sich verfestigende Sinnkristallisation, die in der Dauer des sich entfaltenden Bewegungsbild als Konfiguration ,multidimensionaler Erfahrungsgestalten' entsteht und das Ganze des Wahrnehmungsprozesses umgreift. Auf solche Metaphern bezogen, sprechen wir - wie oben erläutert - äquivalent zum filmischen Bewegungsbild von Cinematic Metaphors oder BewegungsbildMetaphern. ${ }^{31}$

Johnson benennt explizit den Verlust, der sich einstellt, wenn man Metaphern durch ein Strukturmodell kognitiver Systeme zu identifizieren und zu erklären sucht. Sie verlieren genau jenen Aspekt, der sie zum Bestandteil ,unseres Lebens“ macht: die Sinnesqualitäten, die in der Einheit einer multidimensionalen Erfahrungsgestalt avisiert worden sind.

[...] there is a ,down side، to our standard way of describing image schemas. The character of image-schematic analysis that has always worried me since its inception is its exclusive focus on recurring structures or patterns of organism-environment sensory-motor interactions. In short, if you attend only to structure, you necessarily ignore the nonstructural, more qualitative aspects of meaning and thought. You are left with a skeletal structure without the flesh and blood of embodied understanding. You lose, or at least overlook, the very thing that gives image schemas their life, motivating force, and relevance to human meaning, namely, their embeddedness within affect-laden and value-laden experience. There may be no way around this problem, but we can at least recognize what is left out of our theory, without which image schemas could not play their crucial role in conceptualization and reasoning. [...] the limitations of our exclusively structural analysis of image schemas leave out something of great importance. Conscious life is very much an affair of

30 Cavell: The World Viewed, S. 72.

31 Müller/Kappelhoff: Cinematic Metaphor. 
felt qualities of situations. The human experience of meaning concerns both structure and quality. [...] When we describe the image-schematic structure alone, we never capture fully the qualities that are the flesh and blood of our experience. ${ }^{32}$

Das Fleisch und Blut unserer Erfahrung, deren volle Sinnesqualitäten, das sind die Oberflächen medialisierter Interaktionen, auf die sich der Sinn der Metaphern wie der des Bewegungsbildes gründet. Während kognitive Schemata letztlich geschlossene Systeme kognitiver Prozesse entwerfen - Denk- und Fühlautomaten -, zielt die Rekonstruktion von Ausdrucksbewegungen auf die Interaffektivität als ein Netzwerk ineinandergreifender medialer und physiologischer Prozesse ab. Damit einher geht ein grundlegender Perspektivwechsel. In den Blick genommen werden Metaphern und audiovisuelle Bilder als eine Praxis des Sinn-Machens, des Herstellens von Sinn im Gebrauch, d.i. im medialen Konsum - und nicht als Manifestationen bedeutungsgenerierender Systeme. ${ }^{33}$

Wie aber lassen sich die Oberflächen medialisierter Interaktionsprozesse als Gestalteinheit von Erfahrung fassen? Zuschauer, wie ich sie etwa bei REAR wINDOw beschrieben habe, erfahren sich in ihrer Selbstwahrnehmung, d.h. in ihren körperlich-affektiven Reaktionen und projektiven Spekulationen, immer weiter hineingezogen in die dynamisch sich entwickelnden Verstrebungen des Films; sie entwickeln ein Gefühl für das Ganze des filmischen Bewegungsbildes als fiktionale Welt des Films; d.h., sie fingieren dieses Ganze als eine Welt, die der Wahrnehmung der eigenen Alltagswelt entspricht, ohne in ihren inneren Gesetzmäßigkeiten mit dieser identisch zu sein. Eine Analyse der Ausdrucksbewegungen sucht diesen Prozess des körperlich-affektiven Verwickelt-Werdens zu beschreiben. Sie rekonstruiert die audiovisuellen Kompositionsmuster als Einheit von Zeit- und Bewegungsfigurationen. Dabei wird vorausgesetzt, dass sich die Ausdrucksbewegungen den Zuschauern im Prozess der Wahrnehmung als multidimensionale Erfahrungsgestalt, d.i. als Bewegungsbild, erschließen, indem sie - und das ist der alles entscheidende Punkt - als ein Gefühl für den eigenen Wahrnehmungsprozess, ein Gefühl der eigenen Subjektivität erfahren werden.

32 Mark Johnson: The Philosophical Significance of Image Schemas, in: From Perception to Meaning. Image Schemas in Cognitive Linguistics, hrsg. v. Beate Hampe, Berlin 2005, S. 15-33, hier S. 27-28.

33 Kappelhoff/Greifenstein: Metaphorische Interaktion und empathische Verkörperung. 


\section{Ein Gefühl für das Ganze}

Mark Johnson hat ein solches Gefühl für das Ganze der Situation im Blick, wenn er schreibt: „[...] every situation we dwell in is characterized by a pervasive felt quality that is the starting point for all our perceptual discrimination and conceptual definition.“"34

Die Basis aller Erfahrung ist ein Grundgefühl, das die Situation in ihrer Gänze umfasst, eine affektive Einordnung und Verortung des eigenen Selbst in einer gegebenen Erfahrungskonstellation. Johnson bezieht sich mit diesen Überlegungen explizit auf Deweys Konzept der Erfahrung von Kunst. ${ }^{35}$ Die Künste seien, so Johnson, paradigmatische Gegenstände, die geeignet sind, ästhetische Erfahrungsweisen näher zu beleuchten; denn solchen Erfahrungsweisen kommt eine grundlegende Funktion für das menschliche Denken zu:

In the visual arts, it is images, patterns, qualities, colors, and perceptual rhythms that are the principal bearers of meaning. The obvious fact that we usually cannot put into words, what we have experienced in our encounter with an artwork does not make the embodied, perceptual meaning any less a type of meaning. ${ }^{36}$

Johnson trägt hier gleichsam nach, was dem Konzept der image schemas entgeht. Spricht er doch die ästhetischen, d.i. die perzeptiven und affektiven Qualitäten von Kunstwerken nicht als akzidentielle Zugaben zur sprachlich fassbaren, eigentlichen Bedeutung der Sache an. Vielmehr haben sie im konkreten Akt der Erfahrung ihren Wert in sich selbst als ein spezifischer ,Typus von Sinnhaftigkeit‘. Sie sind Impulsgeber einer Erfahrung, die keine vorgängigen Konzepte voraussetzen, sondern den Prozess der Konzeptualisierung erst in Gang setzen und vollziehen. ${ }^{37}$

Präzise einen solchen Prozess fasst Dewey als Erfahrung der Kunst. Er unterscheidet diesen Erfahrungstyp kategorial von den Automatismen alltäglicher, d.h. praktisch-instrumentell ausgerichteter Wahrnehmung. Für ihn stellt die

34 Johnson: The Meaning of the Body, S. 18.

35 Vgl. Dewey: Kunst als Erfahrung.

36 Johnson: The Meaning of the Body, S. 234.

37 Vgl. Christina Schmitt/Sarah Greifenstein/Hermann Kappelhoff: Expressive Movement and Metaphoric Meaning Making in Audio-Visual Media, in: Body - Language - Communication: An International Handbook on Multimodality in Human Interaction, Vol. 2, hrsg. v. Cornelia Müller, Alan Cienki, Ellen Fricke, Silva H. Ladewig, David McNeill, Jana Bressem, Berlin/Boston 2014, S. 2092-2112. 
Kunsterfahrung eine bewusste Reflexion dar, die das eigene Wahrnehmungserleben begleitet, um es in seiner zeitlichen Ausdehnung, seiner Dauer als Einheit zu erfassen. Erfahrung meint dann ein bewusstes Wahrnehmen des eigenen konkreten, sinnlichen Erlebens gegenüber einem Wahrnehmungsobjekt; das Ausfalten eines Objektbereichs zu einem Gegenstand in einem sich zeitlich entfaltenden Gefühl für die Wahrnehmung einer konkreten Sache. Erfahrung meint demnach das reflexive Gewahr-Werden dieses Vorgangs, der sich in der Alltagswahrnehmung automatisiert und ohne bewusste Selbstwahrnehmung für das sich entwickelnde Gefühl vollzieht.

Tatsächlich lässt sich ein solches Modell von Erfahrung zwanglos auf die an REAR WINDOw skizzierte Interaktion zwischen Zuschauer und audiovisuellem Bild beziehen. Erfahrung meint dann eine reflexive Operation, mit der das Sehen und Hören des audiovisuellen Bildes in seiner konkreten Dauer durchlaufen und als multidimensionale Erfahrungsgestalt erfasst wird. Oder mit Blick auf den Körper der Zuschauer formuliert: Erfahrung meint die reflexive Kehre, mit der die unterschiedlichsten Sinnesempfindungen, affektiven Reaktionen und interpretatorischen Projektionen, die den Durchgang durch das audiovisuelle Szenario begleiten, als ein „Gefühl für die Einheit der Erfahrung“38 zusammengefasst werden.

Das die Situation umgreifende Gefühl für das eigene Verwickelt-Sein wird dem Zuschauer zum Gefühl für die innere, die poetische Logik der filmischen Welt. Ein solches ,Gefühl für die Einheit der Erfahrung lässt sich schon deshalb nicht auf ein Set physiologisch determinierter image schemas zurückführen, weil es sich nicht additiv zusammensetzt. Es umfasst vielmehr höchst disparate kulturelle, historische und subjektive Faktoren ebenso wie physiologische und affektive Impulse - Projektionen und Reaktionen, die einzig und allein im reflexiven Umfassen selbst ihre Einheit finden..$^{39}$ Darin unterscheidet es sich auch dezidiert von den wirkungsästhetischen Reaktionsmustern, die von der neuro-kognitiven Narratologie als Emotion oder Affekt angesprochen werden. Erfahrung im Sinne Deweys ist gerade dadurch definiert, dass in ihr die Dauer des Sinneserlebens, seine temporale Struktur, reflexiv als Form des eigenen, subjektiven Empfindens erfasst wird. ${ }^{40}$ Erfahrung fasst den Prozess der Wahrnehmung eines Gegenstandes als multidimensionale Gestalt der Zeit dieses Prozesses; sie erfasst ihn als tempo-

38 Dewey: Kunst als Erfahrung, S. $47 \mathrm{ff}$.

39 Eben dieses Zusammenspiel hat Gibbs im Auge, wenn er den Begriff der embodied simulation auf allen Ebenen, auch jenen des kulturellen und historischen Wissens, in Anschlag bringt. Gibbs: Metaphor Interpretation as Embodied Simulation.

40 Dewey: Kunst als Erfahrung, S. 56. 
rale Gestalt der „Dauer der eigenen Empfindungen“. ${ }^{41}$ Insofern ist sie untrennbar mit dem Akt der Subjektivierung verbunden.

Deweys Erfahrungsbegriff bietet einen Ansatz, filmische Kognition vom bildrepräsentativen Verständnis abzulösen und als Fiktionalisierungsprozess auf die Temporalität der Bewegungsbilder selbst zu beziehen. Die Sinnkonstruktionen gründen dann auf der reflexiven Selbstwahrnehmung im Prozess des Wahrnehmens filmischer Bilder, die man als temporale Form des Gefühls auffassen kann. ,Gefühl' ist dann folglich nicht einfach synonym mit ,Emotion', ,affektivem Appraisal' oder ,Sinnesempfinden“ (Sensation) zu verstehen. Es bezeichnet vielmehr ein intuitives Monitoring (Feeling) ${ }^{42}$ der eigenen emotionalen Reaktionen, affektiven Erregungskurven und wechselnden Sinneseindrücke, das diese mit den kognitiven Operationen reflexiv zu einer Sinnkonstruktion zusammenfasst: eine Konstruktion, die immer einhergeht mit einem Akt der Subjektivierung. Der Fiktionalisierungsprozess in der Interaktion zwischen Zuschauer und audiovisuellen Bildern schließt also immer einen Subjektivierungsakt ein - eine Erfahrung der Einheit des Gefühls für sich selbst als ein Gefühl für die gegebene Welt.

\subsection{Embodied Moving Images: Die affektive Verwicklung der Bildrezipienten}

Erst durch die Rekonstruktion der affektiven Verwicklung des Rezipienten, die Rekonstruktion der Position, aus der heraus sich das ,Gefühl für das Ganze der Situation“ erschließt, lässt sich überhaupt die Position eines verstehenden Subjektes angeben. Ist dieses doch unauflösbar in seinen körperlichen Empfindungen in den Prozess der Entfaltung des filmischen Bildes verstrickt.

Deshalb muss die Analyse audiovisueller Bilder immer den Weg über die Rekonstruktion des ästhetischen Erlebens gehen - das meint die Rekonstruktion der je besonderen Wahrnehmungsform des audiovisuellen Bewegtbildes (d. h. seine Performanz, also die zeitliche Struktur der Entfaltung des Bewegtbildes in der Rezeption durch den Bildkonsumenten) und seiner inszenatorischen Komposition (d.h. der zeitlichen Figur, als welche die zeitliche Struktur im Prozess der Rezeption zur bedeutungsvollen Gestalt eines filmischen Bewegungsbildes wird).

41 Hermann Kappelhoff: Die Dauer der Empfindung. Von einer spezifischen Bewegungsdimension im Kino, in: e_motion, hrsg. v. Margit Bischof, Claudia Feest, Claudia Rosiny, Münster 2006, S. 205-219.

42 Antonio R. Damasio: Ich fühle, also bin ich. Die Entschlüsselung des Bewusstseins, München 2000. 
Das in der Rezeption als embodied image verwirklichte, kinematografische Bewegungsbild lässt sich gerade nicht aus den isolierten audiovisuellen Bild-Repräsentationen ableiten; vielmehr muss es als eine in der Interaktion von audiovisuellem Bewegtbild und Zuschauern verkörperte multidimensionale Gestalt der Erfahrung des Rezeptionsprozesses gedacht werden.

\section{Zuschauergefühl}

Das Konzept der Ausdrucksbewegung markiert die Schnittstelle zwischen der kompositorischen Struktur audiovisueller Bilder und dem Prozess der Verkörperung im Wahrnehmungsempfinden von Zuschauern. Die prozessuale Struktur der Zuschauerwahrnehmung und die kompositorische Temporalität der Ausdrucksbewegung sind als verkörpertes Bewegungsbild ineinander verschränkt. Sie bilden eine multidimensionale Erfahrungsgestalt.

Die kompositorische Dynamik des audiovisuellen Bewegtbildes materialisiert sich als leiblicher Empfindungsprozess rezipierender Körper. Die sich im Medium audiovisueller Bewegtbilder artikulierende Ausdrucksbewegung gewinnt ihre affektive Realität im Akt der Rezeption als leibliche Empfindung, als Zuschauergefühl. ${ }^{43}$

Das Zuschauergefühl entspricht weder einer einzelnen Affekteinheit noch der summarischen Abfolge verschiedener diskreter Emotionen; es ist vielmehr an die durchgängige Modellierung eines sich über die Dauer einer audiovisuellen Darstellung entfaltenden Gefühls (einer Stimmung, einer Atmosphäre) für das Ganze der Darstellung gebunden. Dieses sich entfaltende Gefühl kann auf vielfältige Weise mit dargestellten Figuren, Handlungen und Objekten verschränkt sein. Doch ist es an keinem Punkt identisch mit den Emotionen oder atmosphärischen Zuschreibungen, die auf der Ebene des Dargestellten repräsentiert werden. Das Zuschauergefühl als Gefühl für das Ganze der audiovisuellen Darstellung bildet selbst den Grund, die Matrix einer fingierten Welt - gleichviel ob damit eine fiktionale oder eine tatsächliche repräsentiert werden soll. ${ }^{44}$ Es umfasst die dramaturgische Logik ebenso wie die kompositorische Anordnung oder die Elemente der diegetischen oder dokumentarisch repräsentierten Welt.

43 Hermann Kappelhoff: Zuschauergefühl. Die Inszenierung der Empfindung im dunklen Raum des Kinos, in: Tränen, hrsg. v. Geraldine Spiekermann, Beate Söntgen, München 2008, S. 195206; Kappelhoff/Bakels: Das Zuschauergefühl.

44 Kappelhoff/Bakels: Das Zuschauergefühl. 
In diesem Sinne ist das filmische Bewegungsbild letztlich selbst als ein Produkt der Poiesis des Filme-Sehens zu begreifen, deren einer Pol die sich entfaltende Bewegungsfiguration (Ausdrucksbewegung), deren anderer der Prozess einer entstehenden, sich wandelnden und vollendenden multidimensionalen Erfahrungsgestalt darstellt. Die Subjektivität, die ,Ich-Position', die dabei ins Spiel kommt, ist also selbst wiederum ein Effekt der Interaktion zwischen dem Rezipienten und dem ästhetischen Konstrukt des audiovisuellen Bewegtbildes: ein Produkt der Poiesis des Filme-Sehens. Sie ist eine spezifische Positionierung und perspektivische Zurichtung der Wahrnehmungsweise des Rezipienten, der sich in seinem körperlichen Selbstempfinden in den Prozess des entstehenden und sich entfaltenden Bewegungsbilds als einer spezifischen, d.h. subjektivierten Wahrnehmungsweise verwickelt sieht.

An dieser Stelle sind zwei grundlegende Abgrenzungen vorzunehmen: Dieses ,Ich' ist einerseits strikt zu unterscheiden von dem empirischen Zuschauer, der die Position eines rezipierenden Körpers einnehmen und sich in die Dynamik des sich entfaltenden filmischen Bewegungsbildes in seinem körperlichen Empfindungsprozess einspannen lassen - sich dieser aber auch jederzeit wieder entziehen kann. Andererseits ist das Zuschauer-Ich jedoch ebenso wenig als impliziter oder idealer Zuschauer zu begreifen; eine Instanz also, der man die völlige Durchdringung des semiotischen Materials oder der auktorialen Intention zuschreiben könnte. Im Gegenteil: das Zuschauer-Ich ist konstitutiv an die innere Verkettung der Zeitlichkeit des audiovisuellen Bildes mit der Zeitstruktur des Empfindungsund Denkprozesses der Körper realer Zuschauer gebunden; an die reale Interaktion zwischen Bild und Rezipient. Es lässt sich weder von der Materialität des Bildes, noch vom Körper der Bildwahrnehmung ablösen und ist nur in der Verschaltung beider Temporalitäten greifbar, jener der kompositorischen Muster des Bewegtbildes und jener des sich entwickelnden Gefühls für das Ganze.

Man könnte vielleicht von einem Kamera-Ich sprechen, so wie man in der Gedichtanalyse von einem lyrischen Ich spricht: eine Subjektivität, die sich dem Ausdrucksgeflecht der sprachlichen Konstruktion verdankt, und die als solche von Lesenden realisiert werden muss, um real zu sein. In diesem Sinne wurde der Terminus in die Filmtheorie eingeführt. ${ }^{45}$ Freilich legt der Begriff die Konsistenz einer intentionalen Ausrichtung nahe, die sich an der Analogie von Kamerablick und subjektiver Perspektive festmacht. Tatsächlich aber kann von einer solchen Konsistenz nicht ausgegangen werden.

45 Dziga Vertov: KINOKI - Umsturz, in: Bilder des Wirklichen. Texte zur Theorie des Dokumentarfilms, hrsg. v. Eva Hohenberger, Berlin 1998, S. 74-86. 
Nun ist das Gefühl des sich In-der-Welt-Befindens weder im alltäglichen Leben noch im Film durch eine homogene Perspektive zu bestimmen und als konsistente diskrete Sichtweise zu fassen; es ist vielmehr selbst ein sich permanent neufigurierendes Verhältnis zwischen subjektiven Befindlichkeiten und dynamisch sich verändernden Umwelten. Wir sprechen deshalb von der Position, die jeder ästhetisch, affektiv und reflektierend involvierte Rezipient in der Interaktion mit dem audiovisuellen Bild als eine spezifische Weise des Hörens und Sehens einnehmen und zugleich herstellen muss - herstellen als sein Zuschauer-Ich. Es bezeichnet eine Subjektivität, die sich gründet auf der affektiven Verwicklung des leibhaften Körpers eines Rezipienten in das audiovisuelle Bewegtbild - ohne mit dem Ich dieses Körperbewusstseins ${ }^{46}$ identisch zu sein.

Das Zuschauer-Ich wird hergestellt in der Interaktion zwischen dem physischen Empfindungsprozess und der zeitlichen Struktur des audiovisuellen Bewegtbildes. Im Letzten ist es Bewusstsein der Differenz zwischen der projektiven Weltsicht des audiovisuellen Bildes und der Welt, die sich als Wahrnehmung meines eigenen Körpers erschließt. Es gründet sich auf das subjektive Erleben eines Gefühls für das Ganze der Situation des eigenen körperlichen Befindens; und ist zugleich Bewusstsein, dass nicht ich es bin, der sich solcherart situiert findet; dass die Art und Weise des In-der-Welt-sich-Befindens, die ich hier und jetzt mit meinen Sinnen realisiere, nicht die meine ist. Ganz im Gegenteil - es ist immer die Subjektivität eines anderen, fremden Ichs.

\section{Doing a Metaphor}

Daraus ergibt sich die analytische Aufgabenstellung: Lässt sich doch die Analyse der ästhetischen Komposition audiovisueller Bewegtbilder, ihrer Oberflächen (Krämer), als affektives Erleben der temporalen Dynamik von Ausdrucksbewegungsmustern durch die Zuschauer qualifizieren. Damit ist zugleich gesagt, dass auch audiovisuelle Metaphern per se eine dynamische Konfiguration affektiver, perzeptiver und konzeptueller Verschränkungen darstellen - d.i. die ästhetische Dynamik zwischen audiovisueller Bildkomposition und rezipierendem Körper -, die es in der Performativität der sich ausfaltenden audiovisuellen Bildkomposition, in ihrer Temporalität als dem Ganzen einer gestalthaften Einheit, zu rekonstruieren gilt.

46 Ich orientiere mich terminologisch an der gängigen phänomenologischen Unterscheidung zwischen Leib als dem Selbstbewusstsein meines eigenen Körper-Seins und dem Körper als dem Objekt, das ich besitze. 
Nun wird das Embodiment eines metaphorischen Konzeptes in der konzeptuellen Metapherntheorie in der Regel nicht als Prozess einer verkörperten Performanz der Metapher gedacht. Vielmehr geht man von einer festgelegten operativen Struktur, dem Mapping, aus, mit dem zwei festumrissene Erfahrungsdomänen verbunden werden. In der Folge wird in zahlreichen Analysen audiovisueller Bilder eine basale strukturelle Dualität im konzeptuellen System vom Typ ,a ist b` angeführt. Ich habe bereits eingangs dargelegt, dass ein solches Vorgehen nur möglich ist, wenn man das audiovisuelle Bewegtbild auf eine Abfolge diskreter abbildlicher Repräsentationen zurückführt.

Sobald wir uns aber auf die zeitliche Struktur des Bewegtbildes als Komposition beziehen, verhält es sich mit den audiovisuellen Metaphern wie in sprachlichen Diskursen: Der einzelne metaphorische Ausdruck ist eingelassen in eine manchmal weitläufig verzweigte Kontextstruktur immer neuer Aspekte einer metaphorischen Übertragung. ${ }^{47}$ Im Falle audiovisueller Bilder - dies wird über das Konzept der Ausdrucksbewegung einsichtig - ist dieser ,Kontext‘ allein vermittels einer Rekonstruktion der zeitlichen Struktur affektiver Verwicklungen rezipierender Körper, d.h. als permanente Abfolge von affizierenden Wahrnehmungskonstellationen, greifbar.

In diesem Sinne hat Gibbs die Metapher nicht als statische Relation, sondern als einen Prozess des doing a metaphor definiert. Mit Blick auf den Film bezeichnet dieses ,doing، die temporale Struktur, in der Zuschauer die Metapher gleichsam aus- oder aufführen. Sie durchlaufen die Zeit der audiovisuellen Bildkomposition als performing a metaphor. Wenn Gibbs behauptet: „people tacitly imagine themselves performing the actions they perceive, which enables them to understand through simulations what other individuals are doing“, ${ }^{48}$ spricht er die enge Verbindung von logischer und ästhetischer Struktur, gedanklicher Operation und affektiver Verwicklung über die Sinnesempfindungen an, die den metaphorischen Prozess in seiner Gänze bestimmt. Gibbs versteht solche Abfolgen als

47 Vgl. dazu auch: Cameron: The Discourse Dynamics Framework for Metaphor; Petra Gehring: Erkenntnis durch Metaphern? Methodologische Bemerkungen zur Metaphernforschung, in: Metaphern in Wissenskulturen, hrsg. v. Matthias Junge, Wiesbaden 2009, S. 203-220.

48 Raymond W. Gibbs: Our Metaphorical Experiences of Film, in: Cinematic Metaphor: Multidisciplinary Responses, hrsg. v. Sarah Greifenstein, Dorothea Horst, Thomas Scherer, Christina Schmitt, Hermann Kappelhoff und Cornelia Müller (in Vorbereitung). Vgl. zum performing metaphor und doing metaphor auch: Raymond W. Gibbs/Lynne Cameron: The Social-Cognitive Dynamics of Metaphor Performance, in: Journal of Cognitive Systems Research 9 (1-2), 2008, S. 64-75 und Thomas W. Jensen: Doing Metaphor: An Ecological Perspective on Metaphoricity in Discourse, in: Metaphor. Embodied Cognition and Discourse, hrsg. v. Beate Hampe, Cambridge 2017, S. 257-276. 
eine Verkettung von embodied simulations der Zuschauer, die über den Prozess der Elaborierung der Metapher (performing a metaphor) in die zeitliche Struktur des filmischen Bewegungsbildes eingewoben sind. D. h., Verkörperung ist hier $\mathrm{zu}$ verstehen als unmittelbare Aktivierung bestimmter affektiver und perzeptiver Konfigurationen durch das im audiovisuellen Bild in Szene gesetzte Wahrnehmungsszenario.

Wenn aber die Materie, in der sich eine solche Verwicklung realisiert, tatsächlich die Körper von Zuschauern sind, wenn sie sich also über Empfindungen und Gefühlsprozesse als ein physisches Affiziert-Sein durch das filmische Bild erschließt, bleibt die Frage, wie sich denn die metaphorische Strukturierung zu dem ,Gefühl für das Ganze، verhält; wie verbindet sich das ästhetische Erleben des Verwickelt-Seins in das filmische Bewegungsbild - wie wir es oben mit Johnson und Dewey als ein Gefühl für das Ganze der filmischen Wirklichkeit gefasst haben - mit dem metaphorischen Konzept?

Zumindest in audiovisuellen Bildern lässt sich die Metapher dann freilich nicht mehr als ein festgelegter Operationsmodus, etwa als Mapping vom Typ a ist b' oder als Blending, formulieren; sie ist vielmehr als eine dynamische Abfolge einander weiterführender, antwortender und verknüpfender metaphorischer Übertragungen zu rekonstruieren. ${ }^{49}$ Die metaphorischen Konzepte audiovisueller Bilder sind der Dynamik des filmischen Bewegungsbildes entsprechend selbst als Prozess eines permanenten Verbindens und Verzweigens zu begreifen, der sich aus einer Vielzahl metaphorischer Übertragungen aufbaut; aus Übertragungen, welche in die Zeit der Rezeption des audiovisuellen Bewegtbildes, d.h. den Prozess der Entfaltung des filmischen Bildes, eingewoben sind. ${ }^{50}$ Die fortlaufend elaborierten metaphorischen Konzepte bestehen häufig aus einer Vielzahl einzelner metaphorischer oder metonymischer Übertragungen, die von bestimmten übergreifenden Konzepten strukturiert werden. ${ }^{51}$

Mit Gibbs könnte man sagen, die Metapher ruft die Abfolge von Wahrnehmungsszenarien auf - und strukturiert die Verwicklung der Zuschauer in das dynamisch sich entfaltende Bewegungsbild, dessen Raum-Zeit-Verhältnisse sich immer auf eine Ich-Perspektive hin ordnen. Mit Blick auf die Theorie des audio-

49 Vgl. Cameron: The Discourse Dynamics Framework for Metaphor.

50 Ganz im Sinne des Verständnisses der Metapher als ,metaphor is doing“ bei Gibbs. Vgl. Raymond W. Gibbs: Our Metaphorical Experiences of Film sowie Gibbs/Cameron: The Social-Cognitive Dynamics of Metaphor Performance und Jensen: Doing Metaphor.

51 Darin entsprechen sie den systematischen Metaphern bei Cameron (vgl. Cameron: The Discourse Dynamics Framework for Metaphor). 
visuellen Bildes habe ich im ersten Teil des Buches bezogen auf solche fingierten Raum-Zeit-Konstellationen vom Bildraum gesprochen.

\title{
Der phänomenologische Begriff der Verkörperung
}

Erst die Verschränkung von audiovisueller Komposition und leibhafter Wahrnehmung im filmischen Bewegungsbild begründet die intersubjektive Struktur audiovisueller Bilder, durch die alle Sinnbildung notwendig hindurchgehen muss:

\begin{abstract}
In a search for rules and principles governing cinematic expression, most of the descriptions and reflections of classical and contemporary film theory have not fully addressed the cinema as life expressing life, as experience expressing experience. Nor have they explored the mutual possession of this experience of perception and its expression by filmmaker, film, and spectator - all viewers viewing, engaged as participants in dynamically and directionally reversible acts that reflexively and reflectively constitute the perception of expression and the expression of perception. Indeed, it is this mutual capacity for and possession of experience through common structures of embodied existence, through similar modes of being-in-the-world, that provide the intersubjective basis of objective cinematic communication. ${ }^{52}$
\end{abstract}

Embodiment meint in dieser Perspektive gerade nicht die generative Ableitung symbolischer Bedeutungskonstruktionen aus physiologisch verorteten Interaktionsschemata zwischen einem Organismus und einer gegebenen Umwelt - wie im oben erläuterten Modell kognitiven Embodiments diskutiert. ${ }^{53}$ Vielmehr wird das audiovisuelle Bild vom Zuschauer, so das phänomenologische Modell, als spezifisches subjektives Wahrnehmungserleben eines anderen Körpers realisiert, das am eigenen Körper zu einem konkreten physisch-sinnlichen Wahrnehmungserleben wird.

Das audiovisuelle Medium erscheint in dieser Perspektive selbst als ein multimodales Empfindungsorgan (Sehen und Hören), das in der affektiven Verkopplung mit einem aufmerksamen, fokussierten, empfindungsoffenen Körper denkender Zuschauer zu einem hybriden Körper wird. Das filmische Bewegungsbild ist der Entwurf einer Erfahrung von Wirklichkeit, dem sich die Körper, die diesen Entwurf als subjektive Erfahrung aktualisieren, immer erst noch hinzufügen

52 Sobchack: The Address of the Eye, S. 5.

53 Vgl. George Lakoff/Mark Johnson: Philosophy in the Flesh. The Embodied Mind and its Challenge to Western Thought, New York 1999. 
müssen..$^{54}$ Das filmische Bewegungsbild entsteht erst in der Aktualisierung einer fremden Art und Weise zu sehen und zu hören, die den Zuschauern zur Erfahrung ihres eigenen Körpers wird.

Bereits auf dieser Ebene lässt sich das audiovisuelle Bewegtbild als metaphorische Konstruktion bezeichnen: Ist doch das Gefühl für das Ganze der fingierten Welt eines filmischen Bewegungsbildes eine metaphorische Übertragung (,experiencing one kind of thing in terms of another experience“). Das reale Selbstempfinden von Zuschauern, d.i. die affektive Verwicklung des rezipierenden Körpers in die Zeitstruktur der audiovisuellen Komposition, wird selbst zum Quellbereich (source domain) einer Übertragung, deren Zielbereich (target domain) die unablässig sich wandelnde, dramatisch sich verändernde Expressivität der audiovisuellen Bildkomposition ist.

In der Expressivität des filmischen Bildes tritt dem Zuschauer immer schon ein anderes Ich entgegen, das sich in spezifischer Weise auf Wirklichkeit bezieht und als subjektive Erfahrungsweise zum Ausdruck bringt; es kommt mir als etwas entgegen, das ich als eine Erfahrung der Wirklichkeit, als ein Wahrnehmen und Denken erlebe, welches sich von meiner Erfahrungsweise der Wirklichkeit unterscheidet, obwohl ich sie als eigenes leibliches Sinneserleben reflektiere: Ich erlebe meine physischen Empfindungen, als ob es der Körper jener Wahrnehmung wäre, die mir im audiovisuellen Bewegtbild als die Wahrnehmung eines anderen begegnet. ${ }^{55}$

Filmische Bewegungsbilder können deshalb aus unserer Sicht immer nur als ein Wahrnehmungsereignis beschrieben und analysiert werden, das durch die reflexive Vervielfältigung der Modi und Perspektiven differierender Erfahrungsweisen strukturiert ist; sie lassen sich weder als Text, noch als Bild von den lebendigen Körpern ablösen, in denen sie sich als ein Prozess des Wahrnehmens, Fühlens, Denkens ereignen. Wenn wir über audiovisuelle Bilder sprechen, dann betrachten wir folglich weder textuelle noch narrative Strukturen, die objektiv für sich bestehen, sondern rekonstruieren vielmehr die audiovisuellen Bewegtbilder als filmische Bewegungsbilder, d.h. als ein audiovisuelles Skript, das einem zeitlich strukturierten Kalkül folgend Wahrnehmungsempfindungen und Affizierungen

54 Der Körper des Zuschauers wäre immer schon als bereits ausgeliehener Körper, ein „Leihkörper“ zu denken, er lässt sich nicht auf die Dichotomie von empirischen Zuschauern und audiovisuellem Bild zurückführen. Vgl. Voss: Der Leihkörper, deren phänomenologischer Versuch zur Filmtheorie von dieser Dichotomie ausgeht.

55 Vgl. Kappelhoff/Greifenstein: Metaphorische Interaktion und empathische Verkörperung, S. $169 \mathrm{ff}$. 
ebenso wie verstandesmäßige Konzeptbildungen und Verstehensleistungen auf eine bestimmte Wahrnehmungsweise hin strukturiert und perspektiviert. ${ }^{56}$ Diese Position muss von den Zuschauern eingenommen werden, sofern sie überhaupt das audiovisuelle Bild rezipieren.

Der Körper des Zuschauers wird zum Leib eines Gefühls für das Ganze der filmischen Welt - das Gefühl für die Welt in der Wahrnehmung eines fremden, anderen Ichs. Er leistet in gewisser Weise die subjektive Perspektivierung des Denkens der Bilder im Prozess der Aneignung. Denn das Denken filmischer Bilder ist - das habe ich im ersten Teil des Buches ausgeführt - aus unserer Sicht nicht auf einen Ort gesicherter Autorenschaft zurückzuführen. Noch das Machen der Medienmacher wäre aus dem Prozess der Aneignung filmischer Bewegtbilder heraus zu begreifen; es ist in der Teilhabe am Diskurs filmischer Bewegungsbilder und aus diesem Diskurs heraus immer schon Poiesis des Filme-Sehens - ein Umstand, der nirgendwo so deutlich hervortritt wie im Autorenfilm.

\subsection{Doing Metaphors: DER KRIEGER UND DIE KAISERIN}

Ich möchte dies an einem Film etwas genauer erläutern, der den Moment des Verliebens, des falling in love, tatsächlich als einen Autounfall in Szene setzt. Das Beispiel entstammt dem deutschen Autorenkino: Es handelt sich um Tom Tykwers DER KRIEGER UND DIE KAISERIN (D 2000). Die Sequenz, die ich genauer betrachten will, gilt der ersten Begegnung der Protagonisten. An der Inszenierungsweise möchte ich die permanente Vervielfältigung der Ich-Perspektiven erläutern, die ausgehend vom subjektiven Wahrnehmungsempfinden tatsächlicher Zuschauer eine multiperspektivische Erfahrungsgestalt entstehen lässt. Ohne die schöpferische Resonanz des Zuschauens, ohne die Poiesis des Filme-Sehens, zerfielen die Bildkompositionen in audiovisuelle Daten und abbildliche Repräsentationen.

Ich will zunächst eine Inhaltsangabe zitieren:

Auf narrativer Ebene betrachtet, erzählt DER KRIEGER UND DIE KAISERIN die Geschichte der in der geschlossenen psychiatrischen Anstalt geborenen, wohnenden und arbeitenden Krankenschwester Simone „Sissi“ Schmidt (Franka Potente), deren Leben bei einem schweren Autounfall vom Ex-Soldaten Bodo Riemer (Benno Führmann) gerettet wird. Sissi verliebt sich dabei in Bodo und sieht im Zusammensein mit ihm die Möglichkeit, ihre hermeti-

56 Das hatte Metz im Auge, als er davon sprach, dass die Beziehung der Zuschauer zum Film als eine Aneignung zu verstehen sei, die den Film gleichsam als Liebesobjekt vereinnahmt - während die Analyse dieser Beziehung ihre analytische Zerlegung erfordert, sprich die Zerstörung des Films als Objekt liebender Aneignung. Vgl. Metz: Der imaginäre Signifikant, S. 69 ff. 
sche Psychiatriewelt und die an ihr emotional hängenden und oft dominierenden Patienten verlassen und „draußen glücklich“ werden zu können. Doch Bodo - nach dem gewaltsamen Verbrennungstod seiner Frau aufgrund einer Tankstellenexplosion traumatisiert und beziehungsunfähig - blockt zunächst ihre Versuche, Kontakt mit ihm aufzunehmen, brutal ab. Sissis und Bodos Wege kreuzen sich in der Folge erneut bei einem Bankraub, den Bodo mit seinem Bruder Walter (Joachim Król) begeht, um mit ihm nach Australien auswandern zu können, und bei dem Walter tödlich verletzt wird. Sissi, die ebenfalls an diesem Tag in der Bank ist, kommt hier nun Bodo zu Hilfe. Schließlich - zum Ende des Films - gelingt es beiden dann gemeinsam, ihr jeweiliges altes Leben hinter sich zu lassen und zusammen zu sein..$^{57}$

Der Eindruck, dass es sich um eine recht krude Variation der immergleichen Boymeets-Girl-Erzählung handelt, ist nicht von der Hand zu weisen. Er löst sich auch dann nicht auf, wenn man den Plot detaillierter erzählt, um die handlungslogischen Kurzschlüsse nachvollziehbarer zu machen. Im Gegenteil, die minutiöse Rekonstruktion der handlungslogischen Verknüpfungen der Szenenabfolge lässt das Prinzip dieser Verknüpfungen nur immer absurder erscheinen. Ich zitiere aus eine anderen Inhaltsangabe, die in ihrer Detailgenauigkeit eine surreale Schönheit entwickelt:

Simone (Franka Potente) ist Pflegerin in der psychiatrischen Klinik Stiftung Birkenhof in Wuppertal. Man nennt sie Sissi. Sie hat gerade einen Brief erhalten von ihrer Freundin Meike (Natja Brunckhorst), die in einem einsamen Haus irgendwo am Atlantik wohnt. Meike schreibt, ihre Mutter sei kürzlich gestorben, aber sie wolle wegen der Erbschaft nicht ,den weiten Weg zurück' machen. Deshalb legt sie eine Vollmacht bei und bittet Sissi, damit zur Bank zu gehen.

Bodo (Benno Fürmann) haust mit seinem älteren Bruder Walter (Joachim Król) in einem einsamen Haus auf einem Hügel in Wuppertal. Er versucht sich als Sargträger, doch weil er am Grab weint, wird er gleich wieder entlassen. Walter hat inzwischen im Katasteramt Pläne besorgt und sich Gedanken darüber gemacht, wie sie die Bank ausrauben können, vor deren Haupttresor im Souterrain er Wache hält. Er kennt den Verlauf der Kanalisation und zeigt Bodo, wo dieser einen etwa zehn Meter langen Stollen bis vor seinen Schreibtisch graben kann..$^{58}$

57 Sie stammt aus einer umfassenden Analyse des Films von Christina Schmitt. Meine analytische Skizze entstand anlässlich der Diskussion dieser Analyse in unserer Forschergruppe. Da es sich bei Schmitts Analyse um eine umfassende Darstellung des Films handelt, die exzellent durchgeführt ist, möchte ich mich auf den für meine Argumentation zentralen Aspekt konzentrieren und beziehe mich hinsichtlich der Einbettung in das Ganze des Films auf die Analyse von Schmitt. Vgl. Schmitt: Wahrnehmen, fühlen, verstehen, S. 144-183; die zitierte Inhaltsangabe findet sich auf S. 144 .

58 Dieter Wunderlich: Der Krieger und die Kaiserin. Inhaltsangabe, http://www.dieterwunderlich.de/Tykwer_krieger.htm (02. April 2018). 

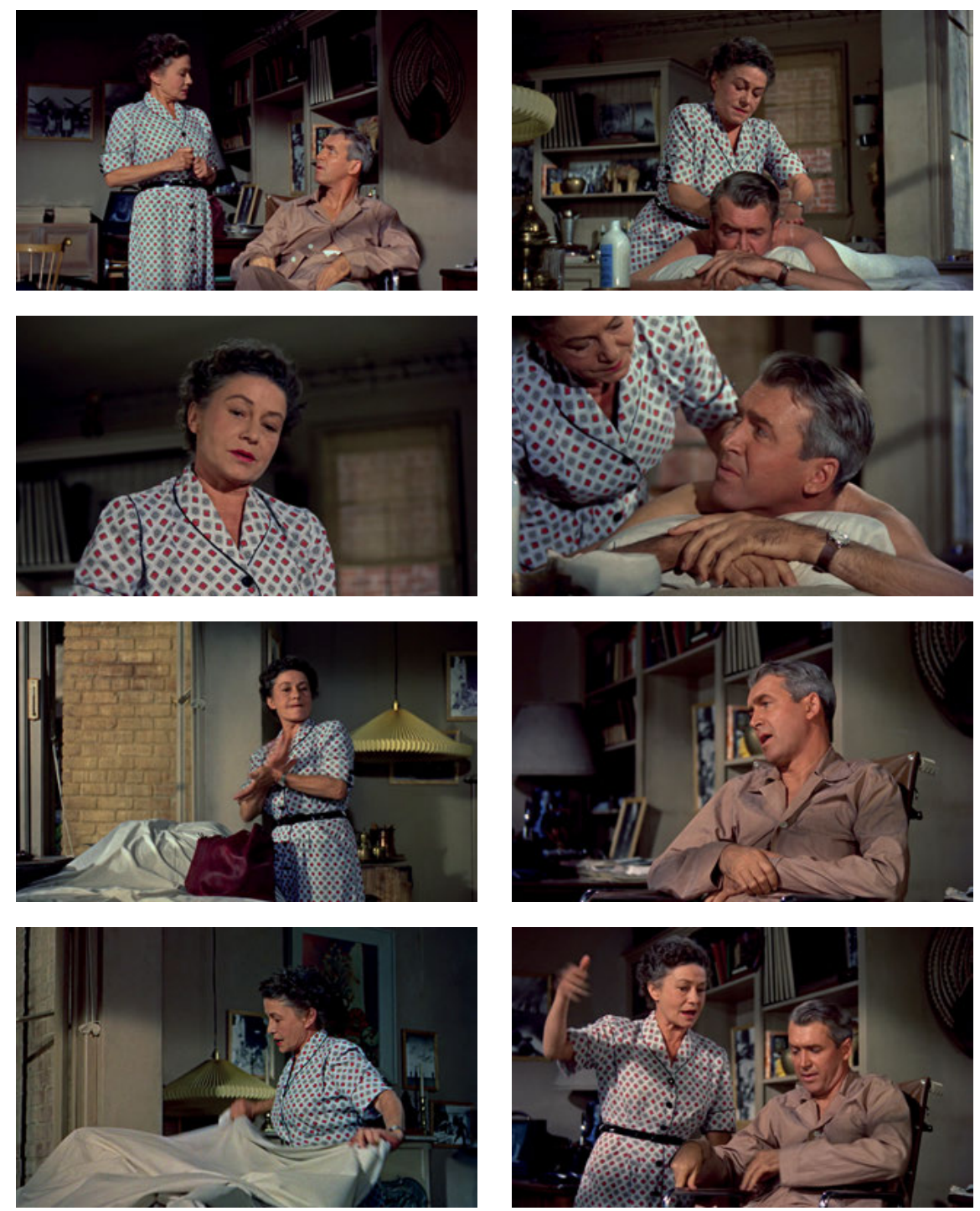

Abb. 11: REAR WINDOW 

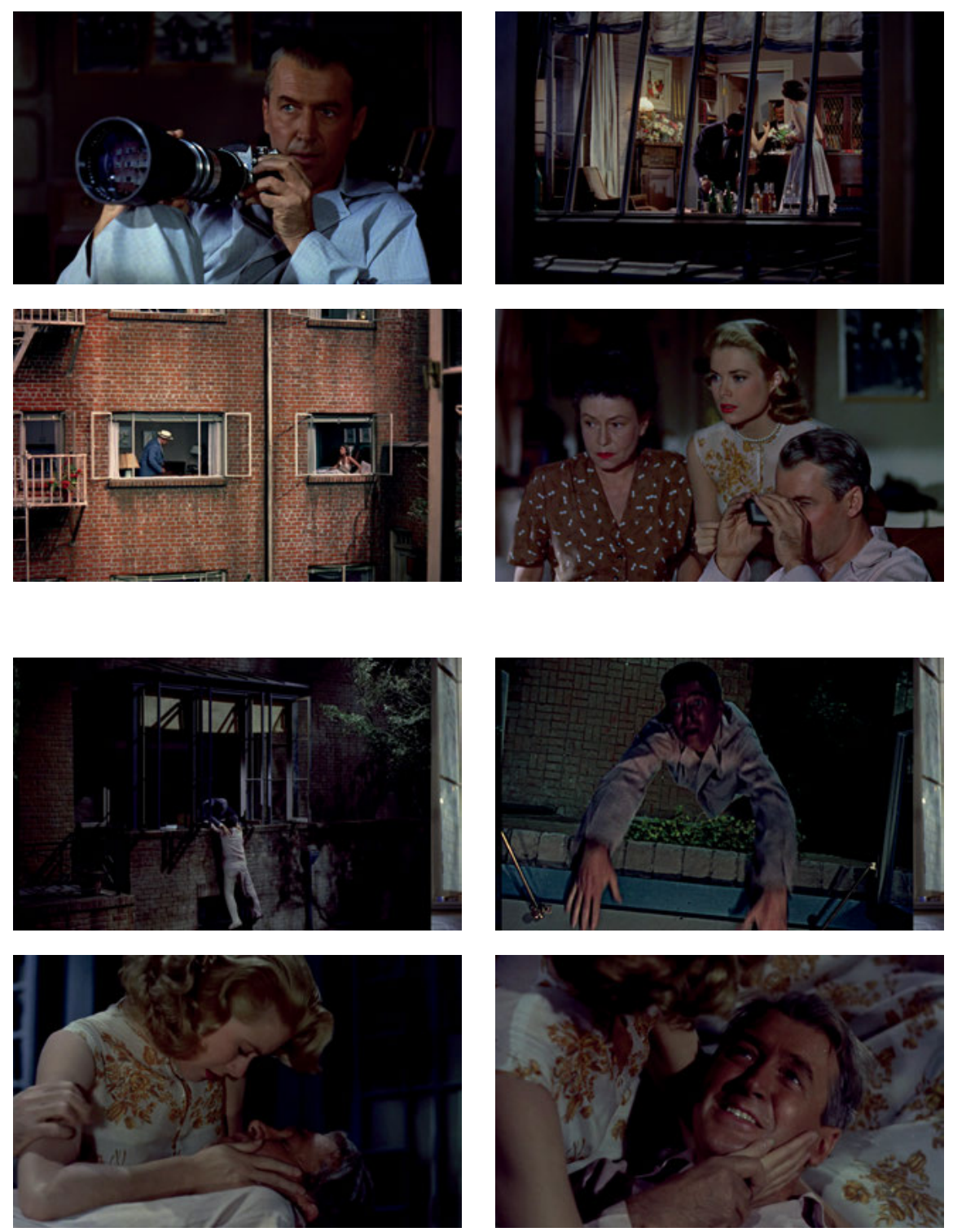

Abb. 12: Faszination des Voyeurs / Fenstersturz 

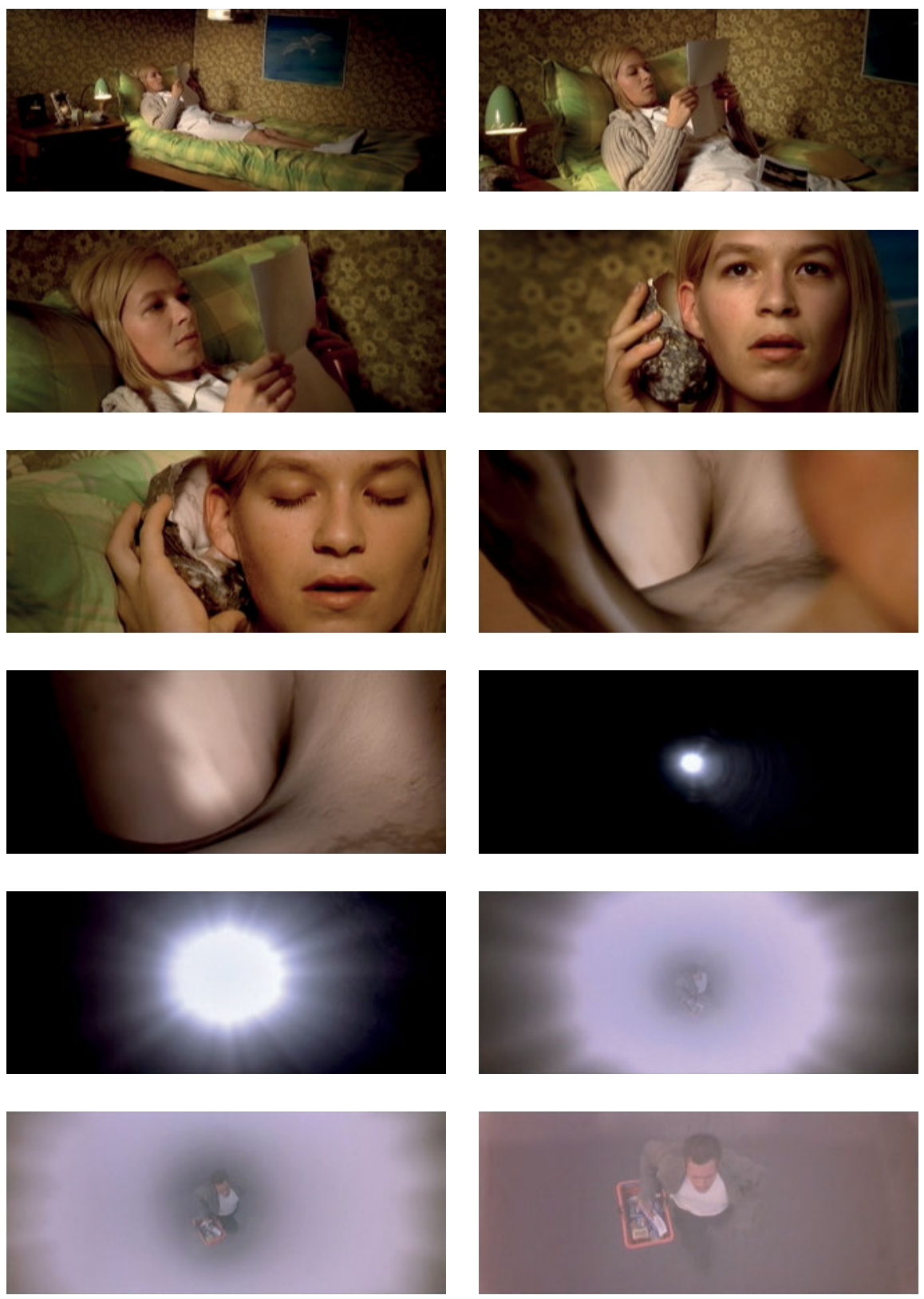

Abb. 14: Metamorphose des Bildraums (DER KRIEGER UND DIE KAISERIN) 

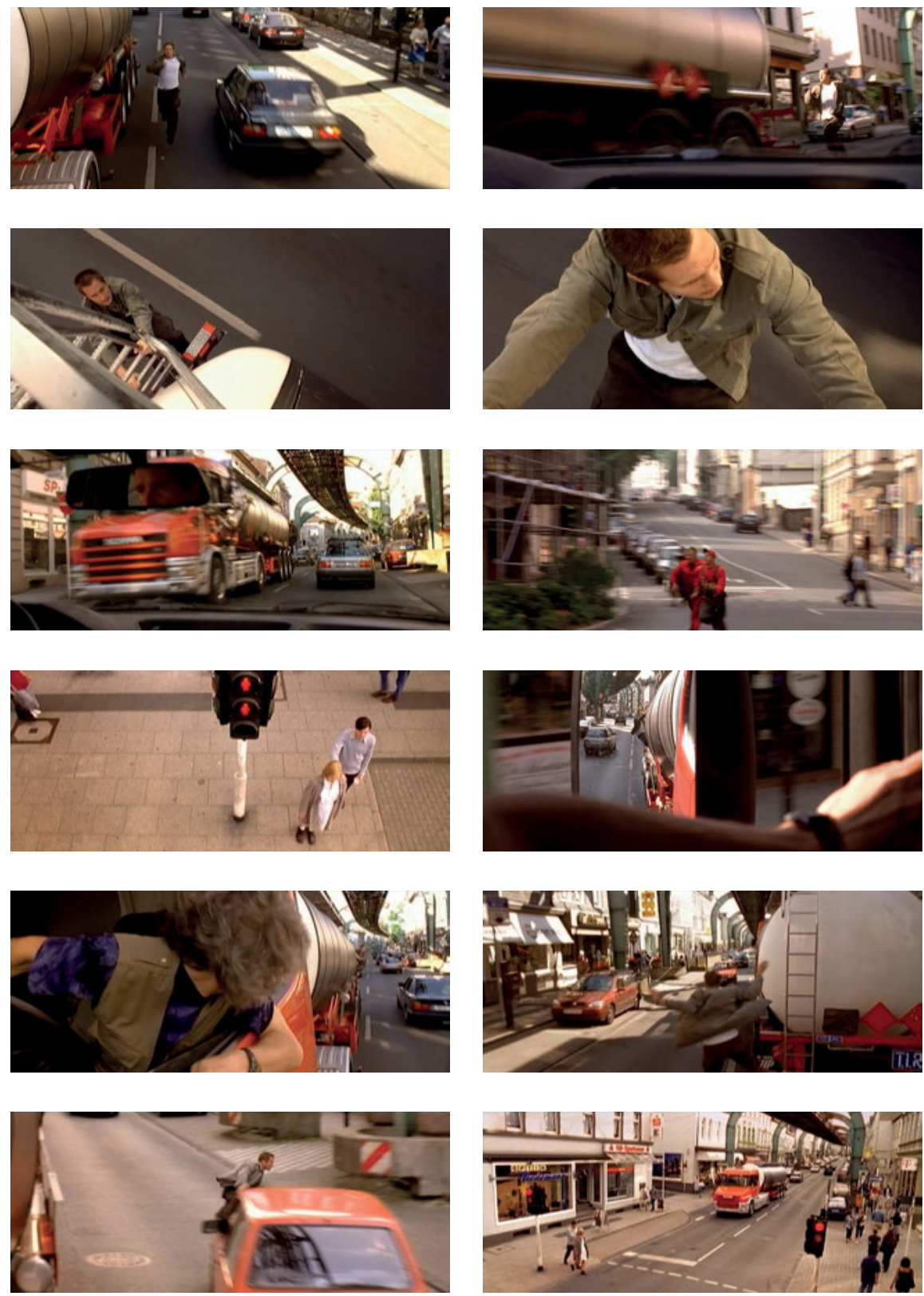

Abb. 15: Die Actionszene 

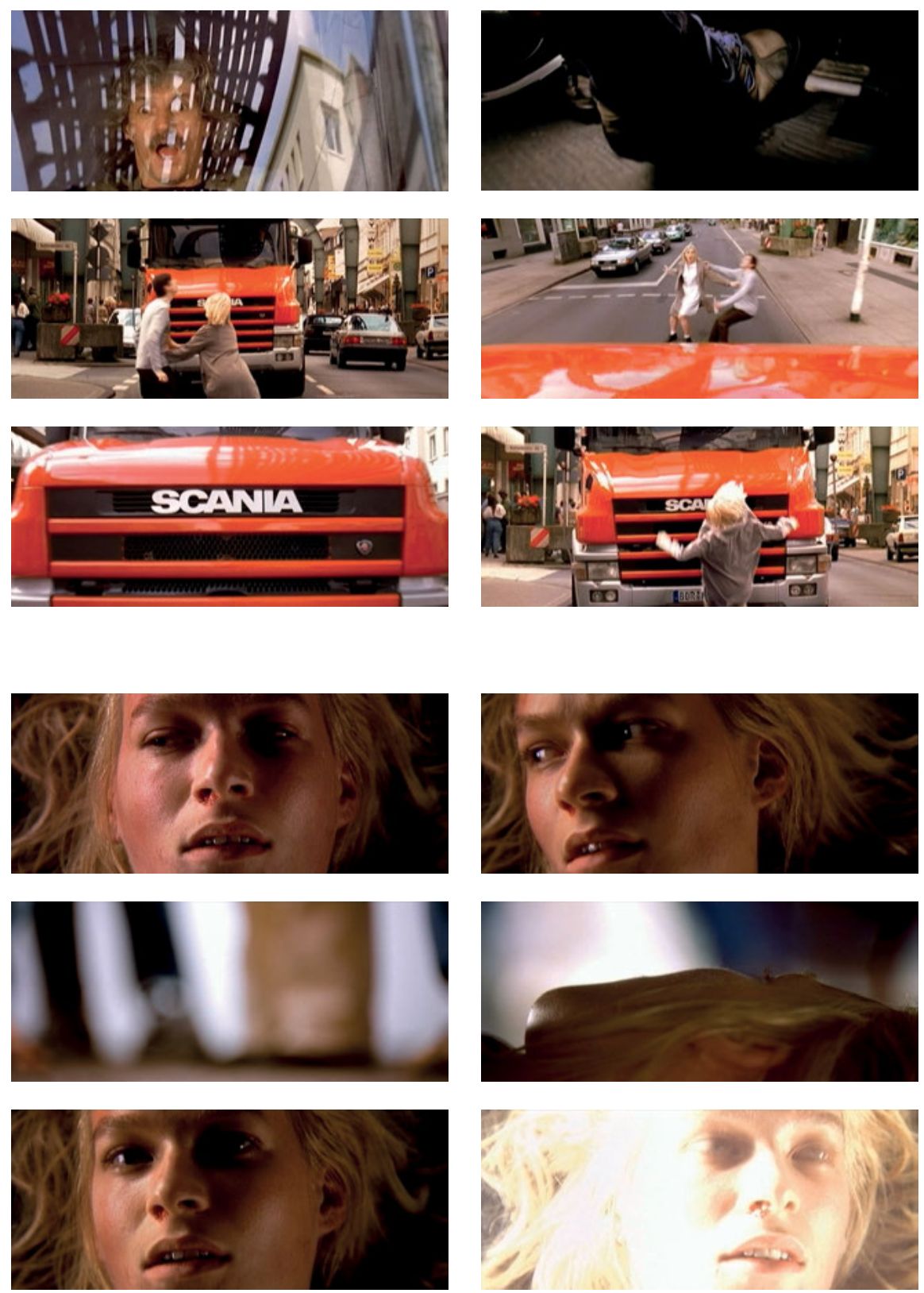

Abb. 15: Die Actionszene 

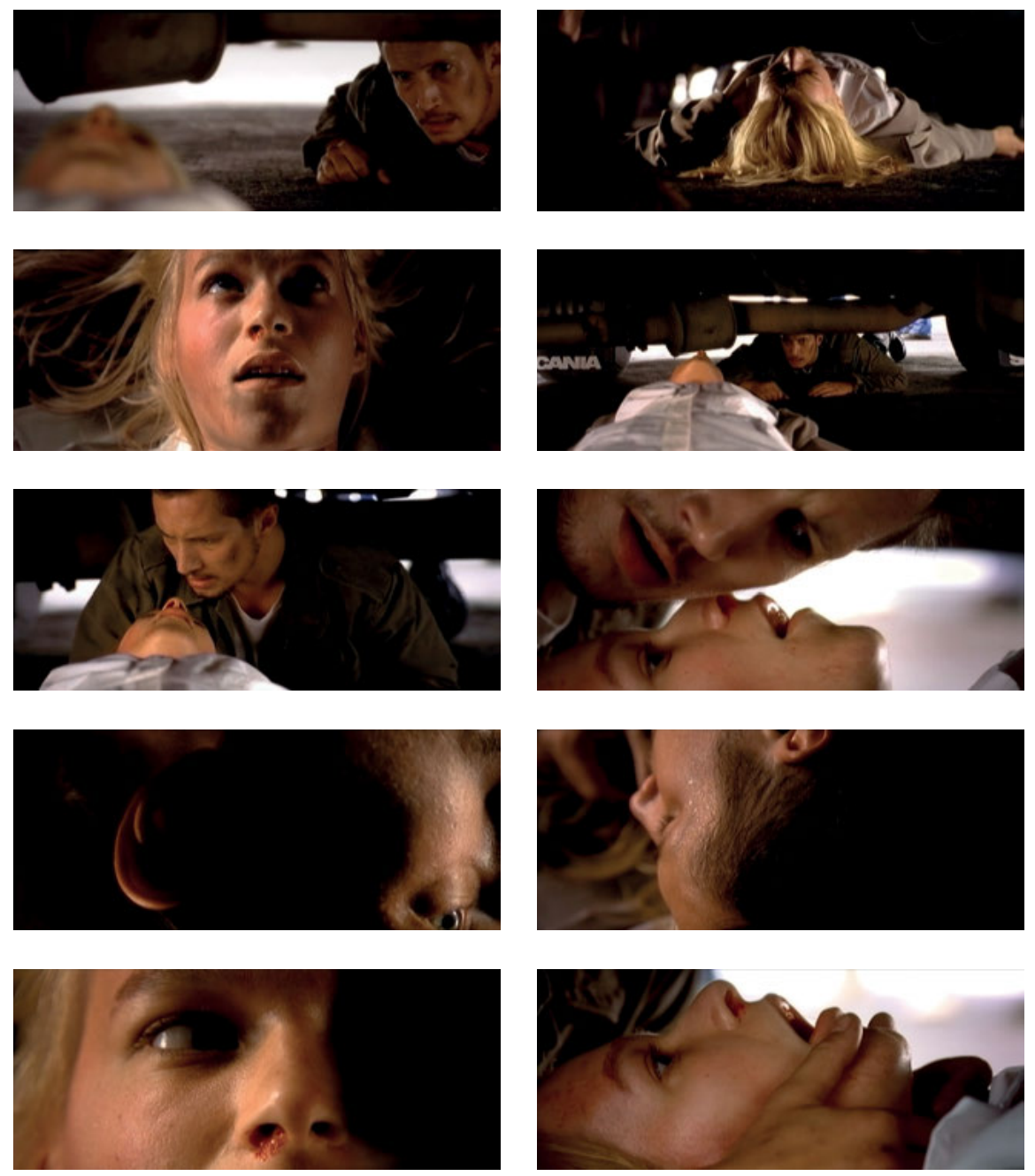

Abb. 16: Rettungsaktion 

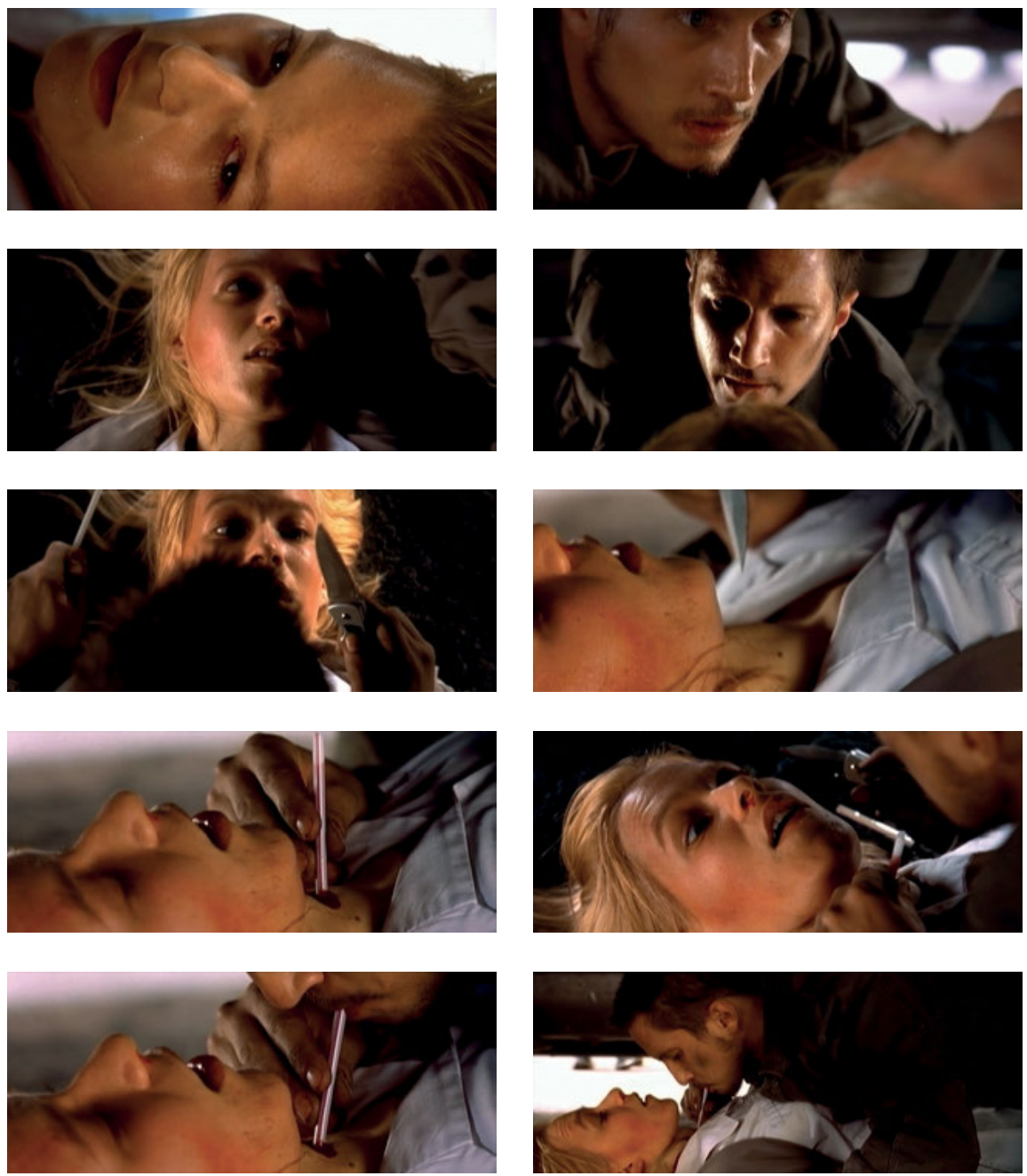

Abb. 16: Rettungsaktion 

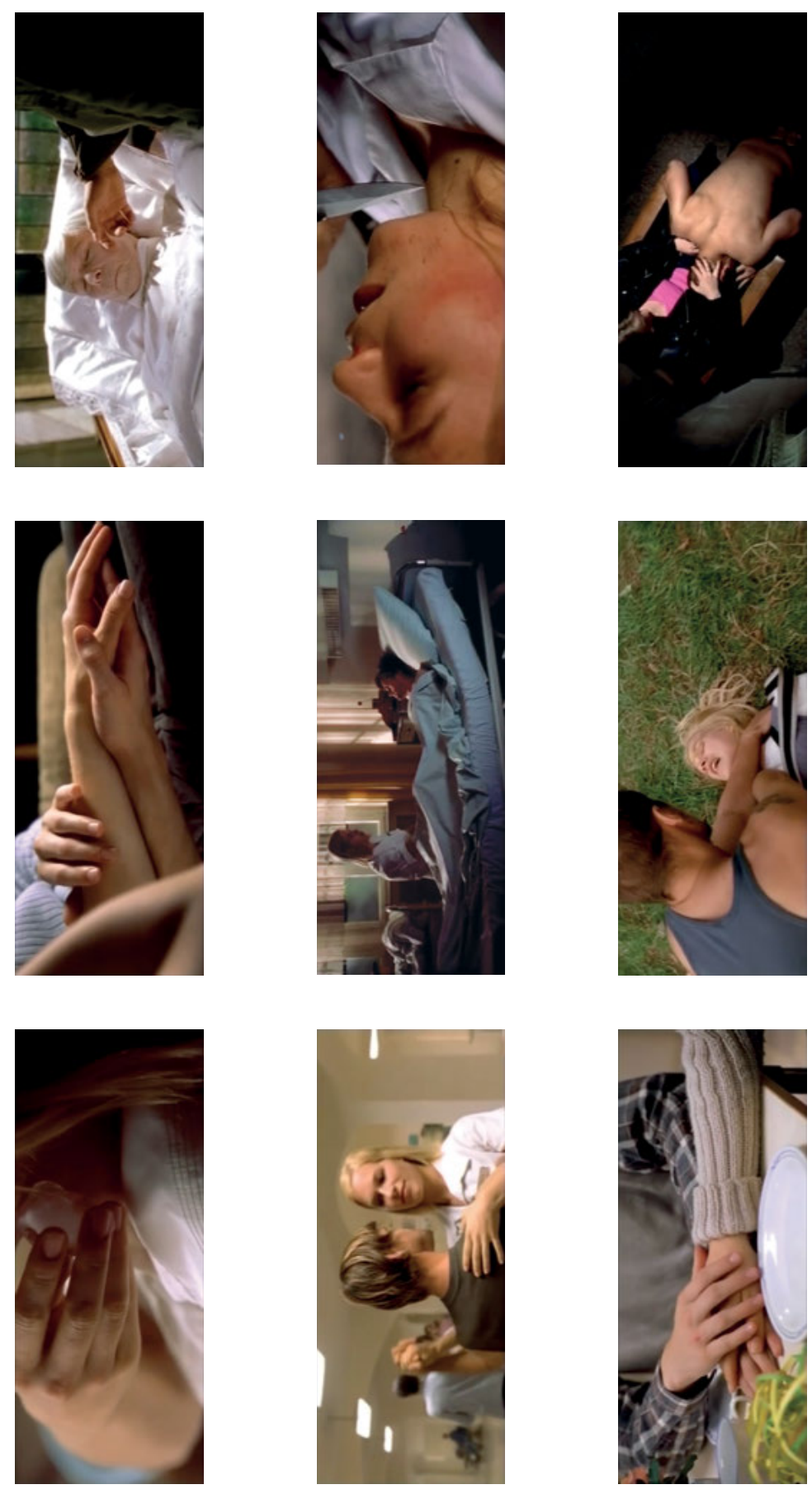

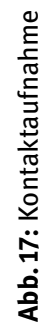


Bei aller Detailgenauigkeit wird man sich nicht des Eindrucks erwehren können, einen völlig anderen Film gesehen zu haben. Das hat seinen Grund. Er betrifft das poetische Konzept, das Inszenierungsprinzip des Films. Gehorcht doch jeder Moment der dargestellten Handlung, jedes Detail des repräsentierten Geschehens einer poetischen Logik metaphorischer Doppelsinnigkeit, die sich nicht auf der horizontalen Verknüpfungsebene der dargestellten Szenen als Handlungsfolge fassen lässt.

Die einzelnen Szenen sind immer schon in-Szene-gesetzte multidimensionale Erfahrungskomplexe, Bildräume, die einem höchst eigensinnigen Prozess metaphorischer Sinnmodulation folgen. Weder lassen diese sich als Subtext einer erzählten Handlung herleiten, noch lässt sich die Handlung Szene für Szene aus der metaphorischen Konfiguration herauslösen - ohne zur Gänze aus der poetischen Logik des Films herauszufallen. Deshalb muss der Inhaltsangabe eine Lesart hinzugefügt werden, die der metaphorischen Doppelbödigkeit einen Namen gibt:

Nicht nur der Titel des Films ist dabei märchenhaft. Auch die Liebessehnsucht Sissis bedient sich auf ganz eigene Weise der Romantik klassischer und moderner Märchenerzählungen. So vermischen sich Dornröschen und Schneewittchen in dem langen, schier ,ewig“ dauernden Moment, in dem Sissi (auf die frontal ein Lastwagen in voller Fahrt aufgeprallt ist) fast wie in einem Sarg unter dem Lastwagen liegt, ohne atmen zu können, und Bodo ihr schließlich mit einem Luftröhrenschnitt das Leben rettet. Und wenn daraufhin Sissi nur noch den Knopf von Bodos Jackenärmel in der Hand behält, bevor sie ihren Lebensretter aus den Augen verliert, und sie sich im weiteren Verlauf des Films dann mit diesem Knopf auf die Suche nach Bodo macht und ihn damit identifiziert, ist das rollenvertauschte Aschenputtel-Motiv offensichtlich. ${ }^{59}$

Man kann zwar die einzelnen Szenen als Handlungsräume identifizieren; doch wird man sie von vornherein als Bildräume begreifen müssen, die in Variationen und Konfigurationen verschiedenster Erfahrungsbereiche den Quellbereich metaphorischer Übertragungen ausarbeiten. Auch die Bildräume lassen sich also keinesfalls als bloße Abfolge unterschiedlicher metaphorischer Konzepte verstehen, die sich zu einer doppelbödigen Narration fügten, sondern sind je zu beziehen auf das Ganze des Films. Erst von dorther - vom Ganzen der Komposition eines Films - lassen sich die unterschiedlichen Erfahrungsdimensionen eines metaphorischen Komplexes auseinanderfalten: Der Zusammenhang des Sinns erschließt sich allein in der Durchführung der Metapher, in der Performanz des doing a metaphor.

59 Schmitt: Wahrnehmen, fühlen, verstehen, S.144f. 


\section{Multiperspektivisches Wahrnehmen}

Die Szene, auf die ich mich nun beziehen möchte (0:15:52-0:25:47), lässt sich handlungslogisch wie folgt verorten:

$\mathrm{Zu}$ einer zufälligen oder schicksalhaften Begegnung von Bodo und Sissi - je nachdem, wie man es sieht - kommt es, als die Pflegerin mit dem blinden Patienten Otto (Melchior Beslon) einen Spaziergang macht. Die beiden überqueren gerade eine Straße, da nähert sich ein Lastwagen, dessen Fahrer durch eine Beobachtung im Rückspiegel abgelenkt ist. Sissi kann Otto gerade noch zur Seite stoßen, gerät aber selbst unter das Fahrzeug. Bodo, der vor irgendwelchen Männern flieht, versteckt sich unter dem am Unfallort stehen gebliebenen Wagen. Als er merkt, dass die neben ihm liegende Verletzte keine Luft kriegt, kriecht er unter dem LKW hervor, besorgt sich ein Messer, reißt einem Jugendlichen den Strohhalm aus dem Cola-Becher und rettet Sissi durch einen beherzten Luftröhrenschnitt vor dem Ersticken. ${ }^{60}$

Soweit also die Szene in der handlungslogischen Perspektive. Bezogen auf die Inszenierungsweise erkennt man auf den ersten Blick eine Kombination verschiedener Rhythmen und Tempi, die unterschiedlichen Modi des Genrekinos zuzuordnen sind: Bodos Flucht wird tatsächlich nur so weit motiviert, dass wir einen Einkaufskorb mit Lebensmitteln erkennen, die einen misslungenen Ladendiebstahl andeuten. Sie wird unmittelbar als das Genremotiv der Verfolgungsjagd aufgerufen: eine klassische Kintopp-Szene in der Instrumentierung des gegenwärtigen Actionkinos; die dynamische Montage einer Folge sehr kurzer Einstellungen, die durch schnelle Kamerabewegungen und die fahrenden Autos in ihrer Bewegungsintensität eine weitere Steigerung erfährt.

Die Hatz durch den Straßenverkehr von Wuppertal, zwischen fahrenden Autos und LKWs, immer knapp am Unfall vorbei, folgt als rhythmisch forcierte Komposition auf die stetige Verlangsamung der vorherigen Szene: Sissi liegt auf dem Bett; sie liest den in der Inhaltsangabe erwähnten Brief, das akustische Motiv vom Beginn des Films begleitet sie: eine minimalistische Variation von Tonfolgen, in der man das Ticken eines Metronoms zu hören meint. Man hört die Stimme der Briefschreiberin: „Draußen rauscht es.“ Eine Hand greift nach einer großen Meeresmuschel. „Genauso wie in deiner Muschel. Nur lauter. Wir wollten immer ans Meer wegen deiner Muschel, weißt Du noch?“ Ein Foto zeigt eine Frau, angelehnt an eine Hauswand. „Und jetzt habe ich es geschafft.“ Man sieht das Gesicht der Protagonistin, sie hält eine große Muschel ans Ohr; die Kamera rückt ganz nah heran, man hört Meeresrauschen - die Windungen von Ohr und Muschel ver-

60 Wunderlich: Der Krieger und die Kaiserin. Inhaltsangabe. 
binden sich sehr langsam zu einer abstrakten visuellen Figuration; der Blick der Kamera scheint sich zögernd dem Sog in die Tiefe des Gewindes zu ergeben, eine kreiselnde Bewegung - wie ein fallendes Blatt - auf den Lichtpunkt zu, der sich immer mehr weitet ... Wahrnehmbar wird in der audiovisuellen Ausdrucksfiguration eine unbestimmte Sehnsucht, die von den Zuschauern als eigene körperliche Resonanz erlebt wird (siehe Abb. 14, Farbbogen 2).

Mit dieser Szene endet die Exposition von DER KRIEGER UND DIE KAISERIN, soweit sie die Protagonistin betrifft. Sie läuft in einer stetigen, sich verlangsamenden Bewegung aus: Der meditative Soundtrack, die ruhige Stimme im Off, die zögerliche Kamerabewegung, die Modulation des Gesichts der Frau, die Bilder der Lesenden, die auf dem Rücken liegt, die Aufsicht der Großaufnahme, die abstrakte Figuration von Ohr- und Muschelgewinde - das alles vermittelt den Eindruck kontemplativer Versenkung; als tauchten die Zuschauer selbst, ihr Sehen und Hören, ein in die Dunkelheit der Sehnsucht eines anderen Ichs: Alice, die dem Kaninchen folgt.

Das Wahrnehmen der Zuschauer wird von der monotonen Tonfolge hineingezogen in die Tiefe des sich schraubenden Tunnels; am Ende ein winziger Lichtpunkt, der rasch größer wird, als würde sich die Kamera auf einen anderen Schauplatz hin öffnen - immer schneller ... bis in einer Überblendung der rennende Mann erscheint - hineinprojiziert in die Bewegung des immer schneller in sich selbst hingewundenen Kamerablicks - ein Hologramm, das aus dem sich öffnenden Lichtkreis dem in die Tiefe sich windenden Blick entgegenstürmt - bevor die Zuschauer wieder Boden unter den Füßen finden - das taghelle Straßenbild, Bodo, rennend zwischen den Autos auf der Fahrbahn, verfolgt von zwei anderen Männern in roten Overalls.

Die Überblendung suggeriert ein Kontinuum zwischen dem hinabsinkenden Blick und dem rennenden Mann; die Bewegung ist ganz unmittelbar als Ausdrucksbewegung zu greifen, als würde der Handlungsraum in einer einzigen kontinuierlichen Bewegung umgestülpt werden in den Raum einer anderen Szene: eine Metamorphose des Bildraums, in der die Szene des Mannes unmittelbar aus der Szene der Frau hervorgeht.

Dabei ist das Bewegungsbild, die Metamorphose des Bildraums selbst, ebenso deutlich als melodramatischer Ausdrucksmodus akzentuiert, wie die folgende Szene dann durch den Modus des Actionfilms gekennzeichnet ist. Tatsächlich werden die Genremodi in ihrer Gegensätzlichkeit scherenschnittartig dem Mann und der Frau zugeordnet. Sie beschreiben eine poetische Welt - ganz der Logik des Filmtitels folgend -, in der Männer Krieger und Frauen Kaiserinnen sind.

Noch die Dichotomie von Frau und Mann erscheint als rein poetische Logik der Zweiteilung, der Zerlegung des Lichts in das Schwarze und das Weiße. Auf das Ganze des Films bezogen ist damit durchaus das grundlegende Sujet benannt: 
Eine Chemie der Liebe, die Erfahrung des Zertrennt-Seins in heteronome Elemente und die Sehnsucht nach Einheit.

Auch wenn sich beide Szenen keineswegs im strengen Sinn als Parallelmontage erschließen, ist im Gegensatz der Kompositionsprinzipien der Bewegungsbilder, im Gegensatz von Melodrama und Actionmodus, eine Suspense-Struktur etabliert. Der Wechsel zwischen den Modi ist für die Zuschauer selbst schon als eine Kräftekollision erfahrbar, die auf die erste Begegnung der beiden Protagonisten hindrängt; als prallten ohne jeden Übergang zwei diametral entgegengesetzte Musiktypen aufeinander, folgt auf das elegische Pianissimo des sich vergrößernden Lichtpunktes in der Tiefe der Tunnelwindungen mit der unvermittelten Aufblende die furiose Actionszene als Verfolgungsjagd zwischen den fahrenden Autos. Und tatsächlich markiert die Tonebene, im Gegensatz zum Kontinuum der Metamorphose, einen scharfen Umschnitt: Anstelle der minimalistischen Tonfolge instrumentiert ein akzentuiert drängendes und schnelles Perkussionsstück die Hetzjagd.

Für die Zuschauer ist die ganze Zeit klar: Sie werden aufeinandertreffen, Boy meets Girl. Aber wie wird das geschehen?

Ein roter LKW: Für einen Moment hat es den Anschein, als würde er den flüchtenden Mann überrollen, der zwischen fahrenden Autos zu entkommen sucht; dann wird der LKW zum rettenden Deus ex machina: Bodo springt auf das Trittbrett, um gleich darauf, ganz dem Muster des Kintopp folgend, vom Fahrer des Lastwagens entdeckt und beschimpft zu werden.

Erneut kippt die Szene in einen anderen Modus: Sissi tritt an eine Ampel heran, begleitet von einem blinden Patienten, der sich an ihrer Schulter festhält. Buchstäblich betritt sie den Bildraum des Mannes, die Actionszene. Mit ihrem Erscheinen stellt sich eine weitere Genreszene ein, die affektpoetisch nicht weniger klar definiert ist wie die vorherigen - auch wenn Sissi nicht mit einem Kind im Kinderwagen, sondern mit einem Blinden im Schlepptau die Straße betritt. Der Fahrer, von Bodo abgelenkt, sieht die Ampel zu spät, schafft es nicht mehr, den LKW zu bremsen. Sissi stößt ihren Patienten im letzten Moment zurück auf das Trottoir - und wird vom Laster erfasst (siehe Abb. 15, Farbbogen 2).

Eine subjektive Perspektive, man sieht von unten, wie der LKW über Sissi zum Stehen kommt. Dann Schwarzfilm, Stille. Erneut sehen wir eine Großaufnahme der Protagonistin, ihr Gesicht blutig, ihre Haare zerzaust, die einzigen Geräusche sind die Innenwahrnehmungen ihres Körpers, Schlucken, Röcheln, leises Stöhnen. Schemenhaft sieht man die Füße umstehender Schaulustiger, eine klare Offstimme: „Stille, eigentlich fand ich Stille immer schön; aber die hier nicht, da fehlte was; mein Atem.“ Eine vibrierende Musik setzt leise ein, langsam bleicht das Bild aus in weißes Licht; man sieht das Gesicht, die Augen im erlöschenden Bild wie die Augen einer Toten. Man denkt an eine zur Produktionszeit des Films 
unter Cinephilen sehr populäre Fernsehserie - SIX FEET UNDER (Alan Ball, sIX FEET UNDER - GESTORBEN WIRD IMMER, USA 2001-2005) -, in der jede Folge einem Tod galt. Und das Sterben war immer gleich inszeniert: ein Ausbleichen aller Bildkontur, bis nichts mehr da ist als weißes Licht.

Tatsächlich beschreibt die Szene einen Tod, den der Sissi, die für alle eine gute Schwester ist; und in der Folge dann sehen wir in der Rettungsaktion die Wiedergeburt. Auch dies eine Metamorphose. Dass sie sich ebenso an Bodo vollziehen muss, wird dann zum dramatischen Movens des Films.

Ein anschwellender Ton, dann wieder das Perkussionsstück; jetzt entwickelt sich die Szene tatsächlich als Parallelmontage: Bodo, von hinten, immer noch auf der Flucht - endlich erreicht er den Unfallort. Wenn er sich unter die Schaulustigen mischt, verstummt die Perkussion. Ein dumpfes Dröhnen setzt ein; er kriecht unter den LKW, um sich zu verstecken. Wir sehen erneut das Gesicht des Unfallopfers in Großaufnahme, hören erneut Sissis Stimme: „Die Luft kam nicht wieder“; nun eingelassen in den gehaltenen dumpfen Ton. Dann sehen wir Bodo, wie er die Sterbende entdeckt. Was nun folgt, ist eine audiovisuelle Variation höchst intimer Berührungen; eine Folge von Ausdrucksbewegungen, deren visuelle Mitte die Verschränkung der beiden Gesichter in einer Folge dynamischer Ausdrucksfigurationen ist, deren akustisches Zentrum der Atem, das Röcheln und Stöhnen des Unfallopfers bilden. Die Gestaltung der Szene ist im Verhältnis zu dem Sujet, das hier verhandelt wird, von einem ähnlich scharfen Gegensatz geprägt wie zuvor bei der Konfrontation des lyrisch-melodramatischen und des actionbetonten Inszenierungsmodus (siehe Abb. 16, Farbbogen 2).

Tatsächlich vermittelt sich dem Zuschauer im schroffen Antagonismus als ästhetische Erfahrung, was der Film als dramatischen Konflikt durchspielt: Die unendliche Schwierigkeit, sich einander liebend $\mathrm{zu}$ begegnen. Im Verlauf von DER KRIEGER UND DIE KAISERIN wird sich zeigen, dass die Dynamik antagonistischer Kräfte, welche die Sequenz beherrscht, den Film in seiner Gänze bestimmt - an dessen Ende sich Bodo und Sissi in der sachten Berührung ihrer Hände dennoch als Liebespaar begegnen.

\section{Embodied Simulation}

Auf Anhieb erkennen wir eine Vervielfältigung von Perspektiven, die allesamt wie ein Konzert subjektiver Einstellungen auf den Bildschirm projiziert werden. Jede dieser Perspektiven wird - embodied simulation - von den Zuschauern quasi in der Ich-Form als Wahrnehmungsempfinden simuliert: Ich bin die Titelheldin an der Ampel; ich trete auf eine Straße und sehe einen Laster auf mich zurasen; ich drehe mich um - ein Reflex ohne Gedanken - und stoße den Patienten, der sich 
an mir festhält, zurück; ich bin der blinde Mann, eng vertraut mit der Frau vor mir, deren Schulter ich berühre; ich höre quietschende Reifen, ein heftiger Stoß gegen meine Brust lässt mich rückwärts taumeln; ich stürze, ein Krachen, ein Schreien um mich herum; ich bin der LKW-Fahrer, was ist da hinten an meinem Lastzug?; ich schreie den Kerl an, der am Wagen hängt; ich nähere mich der roten Ampel; ich spüre die Schubkraft des tonnenschweren LKWs - es gibt kein Halten mehr, keine Kontrolle; wo ist das Mädchen? ... der Aufprall war nicht zu spüren ...; ich bin der Flüchtende, der hinten am LKW hängt; ich springe, ein Auto rast auf mich zu, Reifen quietschen, nur weg!; ich bin der quietschende Reifen, der über den Asphalt schleift, brennendheiß; ich bin eine tonnenschwere Kraft, die alles überrollt, nichts kann mich stoppen; ich bin eine ohnmächtige Frau, wo bin ich?; ich bekomme keine Luft, alles verschwimmt ... usw.

Das wahrnehmende Subjekt, dem sich jede dieser Perspektiven als Teil seiner eigenen Weltsicht erschließt, ist mit keiner der genannten (oder ungenannten) Personen und Dingen identisch. Es ist auch nicht einfach auf einen Zuschauer zu beziehen, der sich mal mehr, mal weniger engagiert mit der einen oder anderen Perspektive identifiziert. Tatsächlich simuliert die Kamera keine diskreten Perspektiven und Blicke, sie entfaltet vielmehr in dem fließenden Wechsel der Perspektiven ein Sehen und Hören, das die gesamte Szene als dynamische Korrelation unterschiedlichster Erfahrungsdomänen umfasst und zu einer Einheit verbindet.

Das meint eine Einheit der Erfahrung, die immer nur in der Verschränkung von Bewegungsbild und rezipierendem Körper zu fassen ist; es meint jenes heteronome ,Ich nehme wahr', das ich oben als Zuschauer-Ich zu definieren suchte.

Es sind also nicht nur die wechselnden Standpunkte und Perspektiven, welche die Sequenz als ein multidimensionales Erfahrungsmuster strukturieren. Vielmehr ist es das Ganze der audiovisuellen Komposition - die rhetorischen Rückbezüge auf das historisch gewachsene Repertoire filmischer Bewegungsbilder; die dynamischen raum-zeitlichen Muster des Melodramas und des Actionfilms, die Modi der Suspense und der lyrischen Introspektion -, in dem jede dieser Perspektiven und Sichtweisen sich zu einem Ensemble dynamischer Ausdrucksfigurationen fügt. Man kann dieses Ensemble als eine fortlaufende Modulation immer neuer subjektiver Perspektivierungen beschreiben, in der das Ganze der audiovisuellen Komposition zur Gestalt eines multidimensionalen Erfahrungskomplexes wird.

Und diese Gestalt realisieren die Zuschauer in einem Prozess wahrnehmender Verkörperung, den ich oben, wie fragmentarisch auch immer, beschrieben habe: Ich, der Zuschauer, durchlaufe in meinen körperlichen Empfindungsreaktionen die Heterogenität und die Gegensätzlichkeit der verschiedenen Perspektiven der Dinge und Personen - embodied simulation - und realisiere sie als zeitliche Einheit des Kamera-Blicks. Mein Leib wird zum Resonanzkörper des Blicks, 
zum Körper des Zuschauer-Ichs. Die Komposition des filmischen Bildes wird zur Gestalt einer vieldimensionalen Erfahrung, die sich anfühlt wie meine eigene, die aber ihrer Form nach die Erfahrung eines anderen, mir fremden Subjekts ist.

Oder wie es Vivian Sobchack ausdrückt:

[T] he film experience is a system of communication based on bodily perception as a vehicle of conscious expression. It entails the visible, audible, kinetic aspects of sensible experience to make sense visibly, audibly, and haptically. ${ }^{61}$

Und weiter:

It is this mutuality of embodied existence and the dynamic movement of its perceptual and expressive relations with and in the world that provide the common denominator of cinematic communication. ${ }^{62}$

In diesem Sinne lässt sich mit Sobchack das filmische Bewegungsbild als eine Erfahrungsform fassen, dessen Gegenstand die irreduzible Multiperspektivität menschlicher Wirklichkeit ist: „the expression of experience by experience“. ${ }^{63}$

\section{Dynamisierte Ich-Positionen}

Durchaus vergleichbar mit Sobchacks Ansatz hat Félix Guattari die kinematografische Wahrnehmung als eine ebenso fluide wie heterogene Subjektposition beschrieben, die sich in den wechselnden Bewegungsfigurationen und Positionierungen als ein depersonalisiertes ,Ich ${ }^{6}$ erfährt. ${ }^{64}$ In der Terminologie einer Theorie des Begehrens entwirft er das Kino als die „Couch des Armen“ und stellt es der psychoanalytischen talking cure polemisch entgegen: ${ }^{65}$ Beides sind kulturelle Praktiken, die auf vorpersonale Semioseprozesse zurückgehen; beide zielen

61 Sobchack: The Address of the Eye, S. 9.

62 Sobchack, S. 13.

63 Sobchack, S. 3. Merleau-Ponty: Das Auge und der Geist; Linda Williams: Film Bodies. Gender, Genre, and Excess, in: Film Genre Reader IV, hrsg. v. Barry Keith Grant, Austin 2012, S. 159-177; Sobchack: Carnal Thoughts; Marks: The Skin of the Film; vgl. auch Robin Curtis/Gertrud Koch (Hrsg.): Einfühlung. Zu Geschichte und Gegenwart eines ästhetischen Konzepts, München 2009; Christiane Voss: Film Experience and the Formation of Illusion: The Spectator as ,Surrogate Body' for the Cinema, in: Cinema Journal 50 (4), 2011, S. 136-150; Voss: Der Leihkörper.

64 Félix Guattari: Le divan du pauvre, in: Communications 23, 1975, S. 96-103. Dt.: Guattari: Die Couch des Armen. Im Folgenden beziehe ich mich auf die deutsche Übersetzung.

65 Guattari: Die Couch des Armen. 
auf die Modellierung von Subjektivierungspositionen, beide arbeiten mit künstlich eingezogenen Projektionsflächen des Wunsches und Affektübertragungen.

Aber die Psychoanalyse organisiere ihre Praxis um ein „personologisches, an Signifikantenpraktiken des Systems über-angepaßtes, zu ihnen übermäßig hingerissenes Subjekt. Die kinematographische Projektion dagegen deterritorialisiert die perzeptiven und deiktischen Koordinaten. “66 Die talking cure verenge den Strom der unbewussten Wunschaktivität auf das sprechende Subjekt hin; das Kino hingegen öffne die personale Identität auf einen komplexen Besetzungsvorgang. Das Kino sei Wunschproduktion, gerade weil es die libidinöse Aktivität des Zuschauers aus dem Rückbezug auf die repräsentationale Ordnung von Bedeutungskonstruktionen löse - oder anders formuliert, weil es sie freisetzt aus der schematischen Reproduktion festgelegter Systeme der Bedeutungsgenerierung:

Ohne Unterstützung durch die Anwesenheit eines anderen tendiert die Subjektivierung dazu, dem Typ nach halluzinatorisch zu werden, sie konzentriert sich nicht mehr auf ein Subjekt, sie zerplatzt in eine Vielheit von Polen, selbst wenn sie sich auf eine einzige Rolle fixiert. Es geht nicht einmal mehr um ein Subjekt des Aussagens im eigentlichen Sinne; denn was von diesen Polen aus gesendet wird, ist nicht allein ein Diskurs, sondern das sind Intensitäten aller Art, Konstellationen von Gesichtszügen, Kristallisationen von Affekten ... ${ }^{67}$

Die kinematografische Wahrnehmung ermögliche, wie die des Rausches oder des Traums, eine Vielheit von Subjektivierungsprozessen, die nicht auf die sprachlichen Subjekt-Objekt-Relationen rückführbar sind: Sie lässt Dinge zu Personen und Personen zu Dingen, sie lässt aus Fahrzeugen Affekte und aus Handlungen Gegenstände werden. Der Zuschauer bewegt sich vom Empfinden des Auto-Seins zum Quietschen des Reifens, um sich gleich darauf in einem prägnanten Gesichtszug des Fahrers wiederzufinden.

Die semiotischen Komponenten des Films sind im Verhältnis zueinander in einem Gleiten begriffen [...]. Dabei werden relationale, emotive, sexuelle Signifikationen [...] beständig von heterogenen „Zügen der Ausdrucksmaterie“ getragen [...]. [...] in einem dauernden Hin und Her geht man von perzeptiven Kodes über zu denotativen, musikalischen, konnotativen, rhetorischen, technologischen, ökonomischen, soziologischen usw. ${ }^{68}$

Guattari beschreibt die kinematografische Wahrnehmung als einen assoziativen Strom von Affektionen, Ausdrucksfigurationen und Symbolisierungen, an die sich das Sehen, Empfinden und Denken eines begehrenden Körpers heftet; auch

66 Guattari, S. 94.

67 Guattari, S. 94 f.

68 Guattari, S. 91. 
er erfasst sie als eine Produktion der Zuschauer, die ihren Antrieb, ihre transformierende Kraft auf die realen körperlichen Lüste und Begierden gründet. Sie bringt einen Film hervor, der durch das Sehen, Denken und Empfinden eines Körpers hindurchgegangen und mit der Aktivität seines Begehrens kurzgeschlossen worden ist.

So gesehen, lässt sich die Poiesis des Filme-Sehens als eine Dynamik verstehen, mit der die identifikatorischen Besetzungen der Zuschauer aus den fixierten Objekt/Subjekt-Relationen herausgelöst und in eine depersonalisierende und deterritorialisierende Bewegung versetzt werden. Sie entspräche dann einer ständig sich verschiebenden Subjektivierung, einer Produktion fließender IchPositionen und dynamisierter Bildräume: gerade so, wie die oben an einer Schlüsselszene von DER KRIEGER UND DIE KAISERIN beschriebene Metamorphose des Bildraums die raum-zeitlichen Koordinaten fest zuzuordnender Perspektiven in Bewegung versetzt hat.

\section{Die Metapher des Berührens}

Wie aber komme ich dazu, ein filmisches Bewegungsbild überwältigender, tödlicher Gewalt und brutaler physischer Verletzung als ein metaphorisches Konzept zu verstehen, das den Autounfall mit der Erfahrung des falling in love verbindet? Von einem Laster überfahren und die Kehle aufgeschnitten zu bekommen, sind vorderhand keine Erfahrungen, die sich anbieten, um konkret fassbar werden zu lassen, was das abstrakte Konzept Liebe bedeutet - selbst wenn man auf die exaltierte Variante hinaus will und erfahrbar zu machen sucht, was es heißt, der Liebe auf den ersten Blick hoffnungslos zu verfallen.

Und doch spielt die Inszenierung durchweg mit metonymischen und metaphorischen Verweisen, die eine solche Lesart durchaus begründen könnten: Wer will, kann mühelos in der Art und Weise, wie der Mann sich über die Frau legt, ihr die Luftröhre öffnet und einen Strohhalm in die Kehle schiebt, eine abgeschmackte metaphorische Übertragung zwischen lebensrettender erster Hilfe und einem erotischen Assoziationsfeld sehen, das vom Dornröschenkuss bis zur gewaltsamen Entjungferung reicht. Geht es doch in den audiovisuellen Figurationen durchweg um die Öffnung und Penetration eines verschlossenen Körpers. Tatsächlich wird im Verlauf des Films immer deutlicher, dass mit jeder Handlungskonstellation immer zugleich der Schauplatz einer anderen Szene entsteht, in der Ängste, Hemmungen und Ambivalenzen als Gegenspieler der Sehnsucht auftreten, in der die wahrnehmenden Körper der Zuschauer längst verwickelt sind.

In jeder Geste, jedem Satz, jedem Blick, jedem Zug der visuellen Figuration des Ineinanders der Gesichter und Körper unter dem LKW wird der Todeskampf 
auf den Liebesakt durchsichtig: So ist es nur folgerichtig, dass der Moment, in dem Bodo sich abwendet, um Rettung zu holen, wie ein Erinnerungsreflex wiederholt wird: „Ich komme wieder“ - der Mal um Mal wiederholte Satz, sein Blick, bevor er verschwindet, ist selbst wie ein gehaltener dumpfer Ton, der die wachsende Panik instrumentiert: Die Angst, keine Luft zu bekommen, ist die Angst, nach der ersten Begegnung verlassen zu werden.

Von hier aus lässt sich die Szene wie das metaphorisierende Bewusstsein eines hoffnungslos verliebten Ichs verbalisieren: ,Du bist mir begegnet, mit einer Wucht, die mich umgehauen hat, die mir den Atem nahm; das Verlangen nach Dir hat mich überrollt wie ein Schwertransporter; Deine drängende Nähe hat mir die Luft zum Atmen genommen. Ich war benommen vor Angst und Entsetzen. Du hast mich aus der Erstarrung gerettet. Deine Hände haben mir Raum zum Atmen verschafft. Du bist fort; Dein Geruch ist der Raum Deiner Abwesenheit.‘

So sinnfällig sich die Unfallszene in den Assoziationsraum eines verliebten Ichs übersetzen lässt - das metaphorische Konzept wird erst in den Verzweigungen kenntlich, die sich über den gesamten Verlauf des Films ausbreiten. Im Verlauf dieser Variationen werden alle möglichen Formen des Berührens und InBerührung-Kommens - vom kindlichsten Zärtlichkeitsbedürfnis bis zur sexuellen Gewaltphantasie - zu metonymischen und metaphorischen Übertragungen der Liebessehnsucht: Die Sehnsucht nach dem Rauschen des Meeres, von dem die Freundin im Brief spricht, das dann in der Muschel als das Rauschen des eigenen Blutes zu hören ist. In der Spanne verschiedenster audiovisueller Ausdrucksfigurationen des Gestreichelt-, Geschlagen-, Gestoßen-Werdens, in den Variationen des In-Berührung-Geratens, des Verletzt- und Bedrängt-Werdens entsteht ein Bildraum, der sich in Gänze als eine multidimensionale Erfahrungsgestalt fassen lässt, die zum Quellbereich des Sujets von DER KRIEGER UND DIE KAISERIN wird, d.i. die alles bestimmende Sehnsucht nach Liebe.

Erst in der Spanne der performativen Durchführung der Metapher wird die Unfallszene zum Dreh- und Angelpunkt einer ersten Begegnung einander völlig verschlossener Individuen, deren Annäherungsversuche brutal, hilflos, zerstörerisch sind. Alle Variationen des Berührens und Berührt-Werdens münden in eine Darstellung, die so stereotyp wie poetisch konsequent der märchenhaften Logik des Films folgt: Die vorsichtige allererste Berührung einander sich öffnender Liebender. Für den Zuschauer entsteht somit in den Wechselbeziehungen aufeinander bezogener Verkörperungen unterschiedlichster Erfahrungen des Berührt-Werdens eine temporale Gestalt, die ihm als fortlaufende Variation des Quellbereichs eines metaphorischen Konzepts von Liebe greifbar wird: Liebe ist die Schwierigkeit, zu berühren, ohne zu verletzen (siehe Abb. 17, Farbbogen 2). 


\subsection{Embodiment und Intersubjektivität: Das ,Wir` und das fremde ,Ich'}

Folgt man meiner bisherigen Argumentation, lässt sich der Prozess der affektiven Verwicklung des Rezipienten ins filmische Bewegungsbild als eine Interaktion zwischen Bewegungsbild und rezipierendem Körper rekonstruieren; dabei tritt die als eigenes leibhaftes Erleben realisierte mediale Wahrnehmungsfiguration in ein permanentes Wechselverhältnis projektiv erschlossener Erfahrungsperspektiven einer anderen Subjektivität. Methodisch lässt sich dieser Prozess als ein Zusammenspiel von dynamischen Ausdrucksbewegungsschemata ${ }^{69}$ und audiovisueller Metaphernbildung beschreiben. Die metaphorische Übertragung wird als dynamischer Prozess des doing a metaphor gefasst, in dem die perzeptiven, affektiven und konzeptuellen Schemata konkreter Inszenierungsmuster und expressiver Qualitäten audiovisueller Bilder im Rezeptionsprozess als unterschiedliche multidimensionale Gestalten von Erfahrung realisiert und in ihrer Differenz aufeinander bezogen werden.

\section{Multiperspektivisches Embodiment versus Einheit des Denkens}

Die Poiesis des Filme-Sehens meint also einen Erfahrungsakt, in dem die Erfahrungsweise eines anderen Ichs introspektiv, d. h. in der Binnenperspektive dieses anderen Ichs, als eigenes leibhaftes Erleben entworfen wird. Man könnte also durchaus von ,Empathie‘ sprechen; freilich wäre dann die Differenz zwischen einem phänomenologischen und einem (individual-)psychologischen Verständnis der Introspektion zu beachten. Versteht die Phänomenologie Empathie doch als eine intersubjektive Struktur, die den verkörpernden Sinnbildungsprozessen selbst eignet. ${ }^{70}$

69 Zum in diesen Gedanken angelegten Verständnis filmischer Expressivität siehe die Ausführungen zur Ausdrucksbewegung in Kapitel 1 und 2 dieses Teiles der Studie; zum darauf aufbauenden Analysemodell im Hinblick auf die Metaphorizität audiovisueller Bewegtbilder siehe Thomas Scherer/Sarah Greifenstein/Hermann Kappelhoff: Expressive Movements in Audiovisual Media. Modulating Affective Experience in: Body - Language - Communication. An International Handbook on Multimodality in Human Interaction, Vol. 2, hrsg. v. Cornelia Müller, Alan Cienki, Ellen Fricke, Silva H. Ladewig, David McNeill, Jana Bressem, Berlin/Boston 2014, S. 2081-2092.

70 Vgl. Grotkopp: Filmische Poetiken der Schuld; Edith Stein: Gesamtausgabe Bd. 5. Zum Problem der Einfühlung, Freiburg 2008; Adriano D’Aloia: Edith Stein geht ins Kino. Empathie als Filmtheorie, in: montage/av 19 (1), 2010, S. 79-100. 
Die verkörpernde Erfahrung audiovisueller Bilder bezieht sich also auf die Art und Weise, in der ein anderes Subjekt die Welt erlebt: ein fremdes, subjektives Welterleben. Konzeptualisiert wird die Differenz zwischen Fremd- und Selbstwahrnehmung - damit komme ich auf den Ausgangspunkt meiner Überlegungen zur Metapher und zum audiovisuellen Bild zurück - im Modus des ,Als-ob‘: Ich fingiere die andere Weltsicht, als ob es sich um mein eigenes körperliches Wahrnehmungserleben, um mein eigenes Gefühl für das Ganze der situativ gegebenen Welt handeln würde.

Dieses Als-ob bildet die Einsatzstelle, in der die Analyse eines metaphorischen Prozesses der Sinngebung mit der Rekonstruktion der perzeptiv-affektiven Dimensionen des Rezeptionsprozesses sich verschränken lässt. Sind doch an diesem Punkt die phänomenologische Definition des filmischen Erfahrungsmodus (als „expression of experience by experience“71) und die kognitionstheoretische Metaphern-Definition des ,understanding one kind of experience in terms of another kind of experience" unmittelbar aufeinander zu beziehen.

Wie ich einleitend in den Ausführungen zur Cinematic Metaphor vorausgeschickt habe, greifen medial organisierte Wahrnehmung und Metaphorisierung als Prozess des Entwerfens und Fingierens differenter Erfahrungsweisen im Akt der Rezeption ineinander. Die Fiktionalisierung betrifft also keineswegs die Unterscheidung zwischen fiktiven und realen Welten - auch das wurde bereits einleitend gesagt. Sie bezieht sich vielmehr auf das ,Gefühl für das Ganze einer situativ gegebenen Wahrnehmungswelt‘. Das Ganze ist die Fiktion, ein fingierter Zusammenhang, in dem alles mit allem verbunden ist und in einer umgreifenden Welt seinen Platz findet: Sei es in den Modi des dokumentarischen Beschreibens, sei es in den Modi fiktionalen Erzählens.

In diesem Sinne sind Cinematic Metaphors konstitutive Elemente eines Prozesses der Fiktionalisierung, der auf der Ebene von Wahrnehmungsszenarien und nicht auf der Ebene der repräsentierten Handlungen, Ereignisse etc. - zu greifen ist; Szenarien eines Wahrnehmens, die sich einerseits als eine körperliche Realität verhalten, die unserer Alltagswahrnehmung entsprechen und die doch zugleich, in strenger Differenz zu dieser, eine fremde Art und Weise, die Welt wahrzunehmen, fingieren: als ein vom Selbstempfinden der Zuschauer unterscheidbares Gefühl für die Welt. ${ }^{72}$

71 Sobchack: The Address of the Eye, S.3.

72 Wie Ratcliffe ausführt, ist unsere Weltwahrnehmung durch ein grundlegendes Gefühl für die Welt bestimmt, das unser Fühlen und Denken strukturiert. Damit ist ein Verständnis von Empathie angesprochen, das auf die Phänomenologie Edith Steins zurückgeht; der Zugang zu einer fremden Erfahrung wird hier über die Wahrnehmung expressiven Verhaltens begreifbar; 


\section{Zwei Konzepte von Embodiment}

Gerade hier nun zeigt sich die grundlegende Antinomie des kognitivistischen und des phänomenologischen Verständnisses von Embodiment. Für den phänomenologischen Begriff des Embodiment ist die Differenz zwischen Selbst- und Fremdwahrnehmung konstitutiv; deshalb bezieht sich das Als-ob der Erfahrung des audiovisuellen Bildes auf die Interaktion einander getrennt gegenüberstehender subjektiver Perspektiven der Erfahrung. Die metaphorische Struktur audiovisueller Bilder gründet sich also auf der Interaktion heterogener subjektiver Perspektiven. Sie meint die Wechselbeziehungen voneinander klar unterschiedener, heterogener Modi der Erfahrung von Welt. D. h., sie rückt die Differenz zwischen einer je besonderen Erfahrungsweise - die in der Komposition des audiovisuellen Bewegtbildes zum Ausdruck kommt - und der alltäglichen Erfahrungsweise der Rezipienten ins Zentrum.

Wird hingegen im Kontext der CMT von der Interaktion zwischen einer klar umrissenen, konkreten Erfahrung und einer diffusen oder abstrakten Erfahrung gesprochen, werden beide Erfahrungsbereiche innerhalb einer als unproblematisch vorausgesetzten Einheit der kognitiven Operationen verortet. Das metaphorische Mapping wird als Binnenstruktur eines homogenen Denkens entworfen. In dieser Perspektive betrifft das Embodiment einen Interaktionsprozess, der sich zwischen einem solitären Denkautomaten (dem Organismus) und einer homogenen Umwelt vollzieht.

Dass ich das fremde Ich wahrnehme, als ob seine Wirklichkeit der meinen entspricht, ist eine konstitutive Voraussetzung jedes wechselseitigen Verstehens. Die Prämisse selbst wird kaum jemand bestreiten. Nur wird sie kognitionstheoretisch meist als etwas selbstverständlich Gegebenes vorausgesetzt und allen kommunikativen Akten unterlegt.

In der gängigen Lesart der CMT setzt die Metapher zwei geschiedene konzeptuelle Erfahrungsbereiche miteinander in Beziehung, die einem mit sich selbst identischen Denken, unserem Denken, unserer Wahrnehmung und unserer Sprache zugehören. Insofern annonciert bereits der Titel der Gründungsschrift, Metaphors We Live By, ein ,Wir‘, dessen Identität und Konsistenz auf einer bruchlosen Homogenität menschlichen Denkens gründet. Dass eine solche apriorische Setzung bei genauerem Hinsehen höchst problematisch ist, sollte sich auch dem robustesten Realismus erschließen. Lässt sich doch die Realität zwischenmensch-

Matthew Ratcliffe: Feelings of Being. Phenomenology, Psychiatry and the Sense of Reality, Oxford 2008. (Vgl. auch Matthew Ratcliffe: Phenomenology as a Form of Empathy, in: Inquiry 55 (5), 2012, S. 473-495.) 
lichen Unverständnisses kaum als marginale Fehlleistung einer objektiv vorhandenen Einheit unseres Denkens qualifizieren.

Das problemlos gesetzte ,Wir ' hat die konzeptuelle Metapherntheorie letztlich abgedichtet gegen die historisch-kulturelle Dimension menschlichen Denkens. ${ }^{73}$ Die Metapherntheorie wird stattdessen zum semantischen Äquivalent der generativen Grammatik. Im Ergebnis aber gerät der Umstand aus dem Blick, dass Metaphern zunächst und vor allem auf das Problem prekären oder gestörten Verstehens bezogen sind; dass gerade an ihnen die Fragilität unseres geteilten Wirklichkeitshorizonts deutlich wird. Gehört es doch zu den grundlegendsten Erfahrungen menschlicher Interaktion, dem brüchigen Verständnis füreinander durch metaphorische Übertragungen auf die Sprünge zu helfen. ${ }^{74}$

Erneut wird deutlich, welche entscheidende Bedeutung dem Erfahrungsbegriff im Kontext einer Theorie der Metapher zukommt. Denn zum einen setzt Erfahrung tatsächlich die gemeinschaftlich geteilte Wirklichkeit eines ,Wir voraus, die als fragloser Sinnhorizont antizipiert wird. Zum anderen ist Erfahrung immer eine Erfahrung für jemanden, also eine subjektive und partikulare Perspektive auf die Wirklichkeit.

\section{Die Ko-Produktion einer Wir-Perspektive}

Der Umstand, dass wir eine gemeinsam geteilte Wirklichkeit unserer Wahrnehmung selbstverständlich voraussetzen, wenn wir denken, ist nicht zu bestreiten (er ist tatsächlich eine notwendige apriorische Annahme jeder rationalen Kommunikation); doch ist die geteilte Wirklichkeit nichtsdestotrotz keineswegs ein selbstverständlich gegebener Sachverhalt; sie steht faktisch als ,Gefühl für das Ganze der Situation' in jeder Interaktion zur Disposition - als ein Gefühl für eine gemeinsam geteilte Welt. ${ }^{75}$ Die gemeinschaftlich geteilte Wirklichkeit ist - meta-

73 Ich werde noch auf diesen Punkt zu sprechen kommen.

74 Lynne Camerons Arbeiten sind hier einschlägig. Vgl. Cameron: The Discourse Dynamics Framework for Metaphor; Lynne Cameron: Metaphor in Educational Discourse, London/New York 2003; Lynne Cameron: Metaphor and Reconciliation. The Discourse Dynamics of Empathy in Post-Conflict Conversations, New York 2011.

75 Der Begriff des Gefühls verweist also nicht auf körperliche Zustände und Reaktionen, sondern auf ein reflexives Empfinden der Relation zwischen meinem besonderen Körper und den diesen umgebenden anderen Körpern, es meint ein ,Zur-Welt-Sein` (Ratcliffe: Feelings of Being), welches nicht anders zu denken ist als ein In-Gemeinschaft-Sein. 
pherntheoretisch formuliert - selbst noch etwas, das im Prozess des performing $a$ metaphor hergestellt oder doch aktualisiert werden muss. ${ }^{76}$

Damit ist ein Perspektivwechsel in der Metaphernforschung angesprochen, der etwas missverständlich mit dem Label applied metaphor research belegt wurde. Ist damit doch keineswegs eine ,Anwendung ' eines Systems konzeptueller Metaphern oder kognitiver Schemata gemeint, wie sie eingangs kritisch diskutiert wurde. Im Unterschied etwa zum linguistischen Verständnis des Terminus applied linguistics, der ganz allgemein alle Forschung umfasst, die sich mit dem Sprachgebrauch als Anwendung bedeutungsgenerierender Systeme beschäftigt, impliziert die Frage nach der Performativität der Metapher eine praxeologische Wendung. Sie zielt auf die Bedeutungsgenerierung in der je situativen Durchführung, Bildung oder Elaborierung einer Metapher, im doing metaphors oder performing metaphors. Es geht also um den Versuch, die Praxis des Metaphorisierens selbst als eine Poiesis der Sinnproduktion - die dichterische Arbeit der Alltagskommunikation - in den Blick zu bekommen.

Wir lehnen uns mit unserer Forschung dabei an zwei metapherntheoretische Konzepte an, in denen die Dynamik der Diskurse, d.i. im sprachwissenschaftlichen Terminus das konkrete Gespräch, die Texte und Konversationen, zum Gegenstand der Untersuchung werden. ${ }^{77}$

Das erste dieser Konzepte bezieht sich auf Metaphern, die in konkreten Gesprächen auftauchen, eingesetzt oder entwickelt werden. Lynne Cameron hat

76 Wir haben uns diesbezüglich in unserer Arbeit vor allem auf Rorty und Rancière bezogen. Vgl. Hermann Kappelhoff: The Politics and Poetics of Cinematic Realism, New York 2015; Grotkopp: Filmische Poetiken der Schuld, S. 52-72; Lehmann: How does Arriving Feel?.

77 Wir haben in unserer Forschergruppe unsere Position gemeinsam mit Cornelia Müller und in engem Austausch mit Lynne Cameron entwickelt. Vgl dazu die Ergebnisse der Forschergruppe: Müller/Kappelhoff: Cinematic Metaphor; Kappelhoff/Müller: Embodied Meaning Construction; Greifenstein: Tempi der Bewegung; Horst: Meaning-Making and Political Campaign Advertising; Scherer/Greifenstein/Kappelhoff: Expressive Movements in Audiovisual Media; Schmitt: Wahrnehmen, fühlen, verstehen; Schmitt/Greifenstein/Kappelhoff: Expressive Movement and Metaphoric Meaning Making in Audio-Visual Media; Cornelia Müller/Christina Schmitt: Audio-Visual Metaphors of the Financial Crisis: Meaning Making and the Flow of Experience, in: Revista Brasileira de Linguística Aplicada 15 (2), 2015, S. 311-342; Christina Schmitt: Embodied Meaning in Audio-Visuals: First Steps Towards a Notion of ,Mode', in: Building Bridges for Multimodal Research. International Perspectives on Theories and Practices of Multimodal Analysis, hrsg. v. Janina Wildfeuer, Bern 2015, S. 309-325; Regina Brückner/Sarah Greifenstein: The Audiovisual Process of Creating Evidence - Science Television Imagining the Brain, in: Handbook of Popular Culture and Biomedicine. Knowledge in the Life Sciences as Cultural Artefacts, hrsg. v. Arno Görgen, German Alfonso Nunez, Heiner Fangerau, Wiesbaden 2018, im Druck. 
die Performanz des Metaphorisierens einerseits in der Kommunikation von Lehrenden mit ihren Schülern untersucht - also in einer Kommunikationssituation, die durch eine massive Ungleichheit der Position der Akteure gekennzeichnet ist; andererseits hat sie Gespräche im Rahmen sogenannter reconciliation processes zwischen einem ehemaligen IRA-Kämpfer und der Tochter eines Attentatsopfers untersucht. Sie hat jeweils eine Dynamik der Diskursverläufe herausgearbeitet, die durch die Entstehung und Elaborierung von Metaphern grundlegend strukturiert ist. Gerade bei dem Versuch, sich auf eine der eigenen Sichtweise entgegen gesetzte oder unverständliche Perspektive zu beziehen, kommt der Metaphernbildung im Gesprächsverlauf - so Cameron - entscheidende Bedeutung zu. Die Metapher wird dabei gerade nicht als eine gegebene Entität verstanden, die wie ein Instrument intentional eingesetzt wird..$^{78}$

Eine weitere Untersuchungsebene wird mit Cornelia Müllers Forschung zur gestischen Interaktion und der Aktivierung von Metaphern eingezogen. Sie hat einerseits in konkreten gestischen Interaktionen zeigen können, wie die Aktivierung sogenannter schlafender Metaphern mit Prozessen konkreter, d.i. mimisch-gestischer Verkörperung einhergeht: Wenn etwa die Geste des Vortragenden den signifikanten Zug eines fingierten Wahrnehmungsgeschehens aufruft, das als imaginäre Szene den Quellbereich einer Metapher illuminiert, noch bevor dieser in der sprachlich artikulierten metaphorischen Phrase auf einen Zielbereich bezogen wird. An der gestischen Interaktion in konkreten Konversationen wird ablesbar, dass Prozesse der Metaphorisierung grundlegende affektive Vektoren in das Gespräch einbringen, die den aktuellen Kommunikationsverlauf einbetten in eine gemeinsam geteilte imaginäre Wahrnehmungsszene. Diese kann auch dann im gestischen Ausdruck als affektivsinnlicher common ground greifbar werden, wenn sie nicht verbal expliziert und keinem der Gesprächspartner bewusst ist. ${ }^{79}$

In der Dynamik gestischer Interaktion wie in der Dynamik des Diskurses wird deutlich, dass Metaphern im selben Maße Koproduktionen der Akteure einer aktuell gegebenen Interaktion sind, wie sie als strukturierende Faktoren solcher Interaktionen fungieren. Gleichviel ob dabei längst konventionalisierte, schlafende Metaphern aufgerufen werden, gebräuchliche Übertragungsmuster kombiniert und moduliert werden, oder gänzlich neue metaphorische Übertragungen

78 Vgl. Cameron: Metaphor in Educational Discourse; Cameron: Metaphor and Reconciliation. 79 Vgl. das im zweiten Teil des Buches in Fußnote 17 angeführte Beispiel aus Müller/Kappelhoff: Cinematic Metaphor. Experience - Affectivity - Temporality, Kapitel 9; Horst/Boll/Schmitt/ Müller: Gesture as Interactive Expressive Movement. 
entstehen: „Metaphor is not part of a system that is put to use; from a dynamic perspective there is only use. “80

Immer ist es die Aktivität des Metaphorisierens selbst, die das Gespräch als ein interaffektives Geschehen zwischen den Diskursakteuren - ihr wechselseitiges Unverständnis, ihre Differenzen und ihr Bemühen, einander zu verstehen strukturiert und einzubetten sucht in einen gemeinschaftlich geteilten Horizont. Metaphern lassen im Zwischenraum des wechselseitigen Unverständnisses einen gemeinsam geteilten Grund entstehen, von dem aus sich nach und nach die Differenz der getrennten Erfahrungshorizonte erschließen lässt.

Welche neuronalen Grundlagen auch immer die physiologische Basis solcher Interaktionen bilden, der geteilte Sinn, das wechselseitige Verstehen, verdankt sich der Dynamik interaffektiver Prozesse, die ein geteiltes Gefühl für das Ganze der Situation, die einen gemeinsamen Sinnhorizont aktualisieren.

\section{Die performative Intersubjektivität von Metaphern}

In dieser Perspektive lässt sich die Formel der Metapher als ,understanding and experiencing one kind of thing in terms of another' sehr wohl auch auf dynamisch wandelbare Erfahrungsmodi im phänomenologischen Sinne beziehen. Dann nämlich, wenn man die Dynamik der Übertragung genauer betrachtet, die den metaphorischen Konzepten selbst innewohnt. ${ }^{81}$ Um diese präziser zu bestimmen, möchte ich noch einmal auf Blacks metaphorische Interaktion zurückkommen.

Für Black ist das „metaphorische Statement“82 immer an eine offene Interaktion zwischen einem primären und einem sekundären Referenzbereich gebunden; die metaphorische Interaktion gründet sich keineswegs ausschließlich auf Ähnlichkeiten, die realisiert und reproduziert werden, sondern kann selbst solche Ähnlichkeiten neu entdecken und herstellen: „It would be more illuminating [...]

80 Cameron et al.: The Discourse Dynamics Approach to Metaphor and Metaphor-Led Discourse Analysis, S. 67.

81 Vgl. Müller: Waking Metaphors; Cornelia Müller/Susanne Tag: The Dynamics of Metaphor: Foregrounding and Activating Metaphoricity in Conversational Interaction, in: Cognitive Semiotics 10 (6), 2010, S. 85-120; Cameron: Metaphor and Reconciliation; Cameron et al.: The Discourse Dynamics Approach to Metaphor and Metaphor-Led Discourse Analysis; Lynne Cameron: Metaphor and Talk, in: The Cambridge Handbook of Metaphor and Thought, hrsg. v. Raymond W. Gibbs, Cambridge 2008, S. 197-211; Cameron: Metaphor in Educational Discourse.

82 Black: Mehr über die Metapher, S. 386. 
to say that the metaphor creates the similarity than to say that it formulates some similarity antecedently existing. “83 Blacks Vorstellung geht davon aus, dass durch das Erleben des primären Gegenstands (principal subject) bestimmte Merkmale des sekundären Gegenstandes (subsidiary subject) hervortreten, indem nur ganz bestimmte Eigenschaften des ersten auf den zweiten übertragen werden (projected upon $)^{84}$ bzw. dass ersterer bestimmte Charakteristika bei zweiterem filtere (filters), transformiere (transforms) oder auch auswähle (selects). ${ }^{85}$ Entscheidend ist dabei, dass in einem solchen Verständnis der Metapher als dynamische Interaktion zweier Erfahrungsbereiche das bildlich-perzeptive Prinzip eines figurativen Denkens skizziert ist, das nicht auf gegebenen Ähnlichkeitsbeziehungen gründet, sondern diese erst als solche produziert.

Metaphern im Sinne Blacks sind also nicht auf vorab existente, fixe Schemata rückführbar, die als „Bildspende-“ und „Bildempfängerbereich“ ${ }^{86}$ bzw. als Quell- und Zielbereich der Metaphorik zu definieren sind. Vielmehr sind sie selbst als Produkte dynamischer Interaktionen zwischen fiktiven Wahrnehmungsszenarien und Schemata der Alltagswahrnehmung anzusehen, in die unterschiedlichste Bewegungs- und Sinnesqualitäten - und die damit verbundenen Wahrnehmungsempfindungen, Affekte und Gefühle - Eingang finden.

Das Medium der metaphorischen Interaktion ist letztlich immer die empathische Verbindung unterschiedlicher Subjekthorizonte. Der prototypische Akteur, der in der metaphorischen Interaktion getrennte Erfahrungsbereiche verbindet, ist das empathische Ich, das sich über metaphorische Konzepte die Erfahrung eines anderen Ich zu erschließen oder sich einem anderen Ich verständlich zu machen sucht. ${ }^{87}$ Die Dynamik metaphorischer Übertragungen, die Performanz des doing a metaphor, ist immer eingelassen in die Dynamik kommunikativer Interaktionen.

Über die Metaphern werden, so gesehen, nicht zwei statisch verbundene Konzepte, Objekte, Bereiche oder Sachverhalte aufeinander bezogen; vielmehr ist die Metapher selbst das Produkt einer dynamisch sich entfaltenden Konfiguration

83 Max Black: Models and Metaphors. Studies in Language and Philosophy, Ithaca 1962, S. 37.

84 Black, S. 41.

85 Black, S. 42.

86 Vgl. Harald Weinrich: Semantik der kühnen Metapher, in: Theorie der Metapher, hrsg. v. Anselm Haverkamp, Darmstadt 1983, S. 316-339.

87 In diesem Sinne spricht Black davon, dass sein Gebrauch des Begriffs ,Interaktion‘ selbstredend figurativ sei, weil die Metapher immer die Übernahme der Perspektive des metaphorischen Statements durch ein rezipierendes Subjekt impliziert, dessen Denken das Medium ist, in dem sich die metaphorische Interaktion vollzieht. Vgl. Black: Models and Metaphors, S. 28. 
getrennter Erfahrungsbereiche, die als Interface zwischen diskreten subjektiven Erfahrungshorizonten fungieren kann. ${ }^{88}$

Oder mit Blick auf Lynne Camerons Arbeiten formuliert: Die metaphorische Übertragung tritt in der alltäglichen Kommunikation gerade dann hervor, wenn es gilt, die Grundlage für ein wechselseitiges Verstehen überhaupt erst herzustellen. Sie wäre also von ihrer pragmatischen Funktion her zu begreifen: der Funktion nämlich, Verständigung dort zu ermöglichen, wo es keinen problemlos geteilten Erfahrungshorizont, kein selbstverständliches Verstehen gibt. Das doing a metaphor ist nicht als solipsistischer kognitiver Prozess zu denken, sondern als eine Koproduktion unterschiedlicher Akteure, die sich auf nicht deckungsgleiche subjektive Erfahrungshorizonte beziehen.

Anstatt von der Dualität einer mehr oder weniger ,einsinnigen` Übertragung zwischen zwei Erfahrungsdomänen auszugehen, ist die Serie von metaphorischen und metonymischen Übertragungen in der Performanz des Metaphorisierens, dem doing a metaphor als Koproduktion eines geteilten Sinnhorizontes zu rekonstruieren.

\subsection{Die gemeinschaftlich geteilte Wirklichkeit}

Der Horizont unserer gemeinschaftlich geteilten Wirklichkeit, unser ,Wir‘, ist immer prekär. Er kann nicht als ein konstant gegebenes Faktum vorausgesetzt werden; vielmehr ist er immer wieder aufs Neue in der konkreten kulturellen und sozialen Situierung je gegebener subjektiver Perspektiven zu erschließen. Selbst scheinbar evidente Schemata, wie die „Moving Observer Metaphor“ oder die „Moving Time Metaphor“89, beschreiben genau solange eine gemeinschaftlich geteilte Wirklichkeit, bis eine andere Metapher auftaucht, die den Fortgang der Zeit in sinnigerer Weise anders verräumlicht. ${ }^{90}$ Gerade mit Blick auf die kognitiven Schemata der Raum-Zeit-Verhältnisse darf man mit großer Sicherheit für alle

88 Zum triadischen Modell, in welchem der Prozess der Metaphorizität eine entscheidende Rolle spielt, siehe Cornelia Müller: Metaphors Dead and Alive, Sleeping and Waking. A Dynamic View, Chicago 2008.

89 Johnson: The Meaning of the Body, S. 29 und 30.

90 Hat doch Eve Sweetser gezeigt, dass jede sprachliche Interaktion durch die gestisch-körperliche und sprachlich-deiktische Bezugnahme auf multiple Perspektiven gekennzeichnet ist, die völlig heterogen sein können und völlig heterogene Wirklichkeitsbezüge darstellen (vgl. Sweetser: What Does it Mean to Compare Language and Gesture?; Sweetser: Introduction: Viewpoint in Language and Gesture from the Ground Down; Barbara Dancygier/Eve Sweetser: Figurative Language, Cambridge 2014; Sweetser/Stec: Maintaining Multiple Viewpoints in Gaze. 
Zukunft erwarten, dass sie durch gegenteilige Erfahrungen falsifiziert werden. Audiovisuelle Bilder führen uns tagtäglich solche Erfahrungen vor Augen, sofern wir nur etwas genauer auf die Bewegungsbilder selber schauen, und nicht so sehr auf das, was wir in ihnen repräsentiert zu sehen meinen. (Etwa, wenn wir eine Frau sehen, die auf einem Bett liegt, einen Brief liest und nach einer Muschel greift, um sie sich ans Ohr zu halten, und das audiovisuelle Bewegungsbild übergehen, die Melodie des trudelnden Sogs in die Tiefe eines weißen Lichts.)

Der Boden jeder Interaktion entsteht mit der Verständigung über das, was als gemeinsam geteilte Wirklichkeit adressiert werden kann. Genau darin kommt eine Dynamik zur Geltung, die dem metaphorischen Konzept strukturell eigen ist: Man kann das ihre Historizität nennen.

Jedenfalls hat Max Black die Metapher dementsprechend nicht nur als Medium kognitiver Operationen, sondern auch als Agens sich historisch wandelnder, heterogener Erfahrungsmuster und Erfahrungsperspektiven beschrieben: ,[...] some metaphors enable us to see aspects of reality that the metaphor's production helps to constitute." 91

\section{Reflexivität}

Das Übertragen, Aktualisieren oder Variieren von Metaphern kann neue Perspektiven hervorbringen, die das geteilte Verständnis von Wirklichkeit verändern. Genau hier kommt die grundlegende Differenz zwischen dem phänomenologischen und dem kognitionstheoretischen Embodiment-Konzept zum Tragen. In letzter Konsequenz betrifft diese, wie ich im folgenden Abschnitt darlegen will, die Möglichkeit eines Bewusstseins der Differenz von Selbst- und Fremdwahrnehmung, d. i. die Reflexivität menschlichen Denkens.

Wenn Johnson in dem Bemühen, sein Verständnis von Erfahrung zu konturieren, auf Dewey zurückgeht, formuliert er eine höchst instruierende theoretische Spekulation: „For nonhuman animals, meaning is fully embodied.“92 Das

91 Max Black: More about Metaphor, in: Metaphor and Thought, Second Edition, hrsg. v. Andrew Ortony, Cambridge 1993, S. 19-41, hier S. 38. „Aus eben diesen Gründen möchte ich weiter daran festhalten, daß manche Metaphern uns in die Lage versetzen, bestimmte Aspekte der Wirklichkeit zu sehen, zu deren Konstitution die Herstellung der Metapher beiträgt. Das überrascht indessen nicht mehr, wenn man der Ansicht ist, daß die ,Welt' notwendig eine Welt in einer bestimmten Beschreibung ist - oder eine Welt, die aus einer bestimmten Perspektive gesehen wird. Manche Metaphern können eine solche Perspektive erzeugen.“ Black: Mehr über die Metapher, S. 409. Vgl. dazu auch Winkler: Metapher, Kontext, Diskurs, System.

92 Johnson: The Meaning of the Body, S. 135. 
theoretische Konstrukt benennt den Grenzfall des kognitionstheoretischen Verkörperungsmodells: Es entwirft einen Körper, der in seinen Stoffwechselkopplungen mit der umgebenden Welt als ein durch und durch automatisiertes meaningmaking zu denken ist; es entwickelt die Vorstellung eines Bedeutung-Machens, das unmittelbar aus dem Kontinuum der Aktion-Reaktion-Kopplungen eines Organismus mit einer gegebenen Umwelt hervorgeht und also durch keine reflexive Bewusstseinstätigkeit gebrochen ist.

Was vor allem interessant ist an dem metaphorischen Konzept - denn darum handelt es sich wohl, wenn der tierische Körper als ein vollständig verkörpertes Bedeutung-Machen vorgestellt wird -, ist, dass damit die Verkörperung selbst zum Differenzkriterium menschlichen Denkens wird. Nun macht es freilich ganz und gar keinen Sinn, sich Denken als ein ,non-fully embodied meaning-making' vorzustellen; bliebe doch in diesem Fall als menschlicher Anteil des Sinn-Machens nichts anderes zurück als körperlose Operationen im Reich der semiotischen Systeme und Konventionen.

Es ist offensichtlich, dass eine solche Dichotomie innerhalb des Erfahrungskonzepts, das Johnson zu definieren sucht, keinen Platz fände. Tatsächlich beziehen sich seine Überlegungen auf jene Prozesse der Verkörperung, die durch keine physiologischen Mechanismen erklärt werden können. Dewey - auf den Johnson hier rekurriert - entwickelt die Dichotomie denn auch nicht als anthropologisches Differenzkriterium, sondern aus dem Gegensatz von automatisierter Wahrnehmung und Erfahrung heraus. Für ihn markiert das ,Gefühl für das Ganze der Situation', die ich als das wahrnehmende Subjekt in meinen mir selbst gegenwärtigen Empfindungsprozessen umspanne, das entscheidende Kriterium, welches erfüllt sein muss, um überhaupt von Erfahrung zu sprechen.

Hingegen weiß der Körper eines ,fully embodied meaning ‘ nichts von der Differenz seiner eigenen Körperlichkeit gegenüber den ihn umgebenden Körpern, mit denen er interagiert. Ihm fehlt das reflexive Gefühl für sein eigenes Verwickelt-Sein in die Situation, für ein Gefühl, welches das Ganze seiner Reflexe und Reaktionen umspannt.

Die Reflexivität des Gefühls - d.h. der Wahrnehmung des eigenen perzeptiven und affektiven Prozesses -, unterscheidet Erfahrung von einer sich selbst nicht gewahr seienden, automatisierten Wahrnehmung. So gesehen bezeichnet die theoretische Fiktion eines ,fully embodied meaning nichts anderes als die Unterscheidung zwischen einer reflexiven und einer nicht-reflexiven Verkörperung, zwischen einem automatisierten und einer bewusstseinszeugenden Interaktion von Organismus und Umwelt - wobei freilich das eine nicht weniger verkörpert als das andere zu denken ist. 


\section{Ein Bewusstsein der Reflexion}

Die theoretische Spekulation des ,fully embodied meaning' bringt letztlich eine Differenz ins Spiel, die in der Geschichte westlicher Philosophie notorisch traktiert worden ist: Das Bewusstsein. Auch wenn dies mitunter massive Probleme aufwirft, wird man sich der Frage nach einem reflexiven Bewusstsein nicht dadurch entledigen können, dass man die sinnproduzierenden Prozesse menschlicher Interaktion allesamt als ein Zusammenspiel physiologisch-gegründeter oder konventionalisierter kognitiver Automatismen behandelt. Ein bruchloses Ineinander von automatisierten Schemata und konventionalisierten Mustern lässt sich nur dann als Kontinuum kooperierender Aktionen, Reaktionen und Umwelten konzeptualisieren, wenn man jede Brechung durch ein subjektives Bewusstsein des Gefühls für die eigene körperliche Verwicklung in die gegebene Situation ausschließt; d.h., wenn man das Ineinander physiologischer oder konventionalisierter Automatismen tatsächlich als ein ,fully embodied meaning' versteht. (Was durchaus die metaphorische Formulierung eines weit in die Ferne gerückten neurowissenschaftlichen Erkenntnisziels sein mag. ${ }^{93}$ )

Die Phänomenologie geht den umgekehrten Weg. Sie hat die konstitutive Reflexivität menschlicher Wahrnehmung in der Differenz von ,Körper und ,Leib“ geltend gemacht. Zur Erinnerung: ,Leib` meint das Bewusstsein, das das Ganze meiner Sinnesempfindungen und affektiven Spannungen als ein ,Ich bin dieser Leib، umfasst; im Unterschied zum ,Körper‘, den ich besitze und als ein Objekt in einer gemeinsam geteilten Wirklichkeit verorte.

Das Bewusstsein der eigenen Leiblichkeit (Plessner) ist die Grundform des reflexiven Gefühls; es ist Bewusstsein des dynamischen Kontinuums meines Sinneserlebens als ein Gefühl für das Ganze permanent sich wandelnder Situationen, in die ich verwickelt bin. Dies gilt auch umgekehrt: Das Bewusstsein für die eigene körperliche Existenzweise - das Bewusstsein des ,Ich bin dieser empfindende Leib، - verdankt sich dem reflexiven Gefühl für die Verwicklung mit der umgebenden Wirklichkeit; es ist Erfahrung dieses Verwickelt-Seins. Erfahrung bezieht sich, wenn wir Dewey folgen, immer auf die Erfahrung der Eigensinnig-

93 Wenn Lakoff und Johnson versuchen, die Universalität metaphorischer Konzepte anhand des Begriffs der primary metaphor aufzuzeigen, den sie im Verständnis von Joseph Grady beschreiben, dann entscheiden sie sich für diese Richtung: „Primary metaphors are part of the cognitive unconscious. We acquire them automatically and unconsciously via the normal process of neural learning and may be unaware that we have them. We have no choice in this process. When the embodied experiences in the world are universal, then the corresponding primary metaphors are universally acquired. This explains the widespread occurrence around the world of a great many primary metaphors.“ Lakoff/Johnson: Philosophy in the Flesh, S. 57. 
keit der eigenen leibhaften Wahrnehmung, auf meine Subjektivität. Sie bezieht sich im Letzten auf die Grenze zwischen subjektiver und gemeinschaftlich geteilter Realität.

Dann aber bezeichnet das reflexive Gefühl für das leibhafte Verwickelt-Sein in die mich umgebende Welt weniger ein anthropologisches Differenzkriterium als vielmehr den Abstand, der sich zwischen Ich-Perspektive und Wir-Perspektive auftut; zwischen einer fraglosen gemeinsam geteilten Wirklichkeit, in die wir als ein ,Wir' vollkommen eingekörpert sind, und dem Bewusstsein einer ganz und gar eigensinnigen Leiblichkeit.

\section{Lebenswelt}

Blumenberg hat diese Differenz im Sinn, wenn er die fraglos gegebene Wirklichkeit mit dem Begriff der „Lebenswelt“ erfasst. Allerdings verdankt sich sein Verständnis des Begriffs einer durchaus eigensinnigen Rekonstruktion der Husserlschen „Lebenswelt“. Blumenberg hat seine Lesart explizit als Kritik an dem tradierten Verständnis formuliert: Lebenswelt meine gerade nicht den fraglos gegebenen, alltagsweltlichen Lebenszusammenhang; der Begriff ziele vielmehr auf einen rein theoretischen Grenzwert, von dem her die Bedingungen allgemeiner Sinnbildung erst anzugeben sind. Auch Blumenbergs Begriff der Lebenswelt ist also ein theoretisches Konstrukt, das den Grenzfall einer gänzlich fraglos gegebenen Wirklichkeit bestimmt - er spricht deshalb vom „Grenzbegriff““ ${ }^{94}$ Lebenswelt bezeichnet eine Welt, die ohne jede verstandesmäßige Reflexion in jedem ihrer Züge jedem, der ihr zugehört, restlos verfügbar ist. Insofern entspricht die Blumenbergsche Lesart der Lebenswelt durchaus der theoretischen Fiktion eines ,fully embodied meaning،. Nur mit dem Unterschied, dass Lebenswelt genau den Aspekt bezeichnet, der jeder Sinnproduktion als Bezugnahme auf eine unproblematisch gegebene gemeinsame Wirklichkeit mitgegeben ist; während die Sinnproduktion selbst gerade auf das Fehlen eines selbstverständlich gegebenen Bezugs auf eine gemeinschaftlich geteilte Wirklichkeit antwortet.

Für Blumenberg gilt das jedenfalls mit Blick auf die Metapher. Für ihn nämlich markiert die Metapher (wie alle rhetorische Aktivität) den Bruch mit der Kontinuität einer fraglos gegebenen Welt. Mehr noch: Sie geht aus der Erfahrung eines solchen Bruchs hervor. ${ }^{95}$ Machen Metaphern doch nur Sinn, wenn etwas

94 Vgl. Hans Blumenberg: Theorie der Lebenswelt, Berlin 2010, S. 65.

95 Hans Blumenberg: Anthropologische Annäherung an die Aktualität der Rhetorik, in: ders.: Wirklichkeiten in denen wir leben. Aufsätze und eine Rede, Stuttgart 1981, S.104-136. 
auftaucht, an dem die Automatismen oder Konventionen eines ,fully embodied meaning', d.h. eines unbewussten, fraglosen Sinns, sich brechen. Die oben bereits diskutierte These aus Metaphors We Live By liest sich so gesehen durchaus als Bestätigung des vorgetragenen Arguments: „metaphors come out of our clearly delineated and concrete experiences and allow us to construct highly abstract and elaborate concepts [...].“966

Insofern tritt die Metapher immer als Bruch mit dem allgemein Verständlichen in Erscheinung; ${ }^{97}$ mag sich der Versuch, diesen metaphorisierend zu überbrücken, konkret auf das wechselseitige Unverständnis in einer Konversation, die Inkonsistenz eines theoretischen Arguments eines Textes, oder den Bruch mit einer poetischen Tradition beziehen - im Letzten weist die Metapher auf die Brüchigkeit einer gemeinschaftlich geteilten Wirklichkeit zurück.

Wenn der Titel Metaphors We Live By nicht im aleatorischen Sinne metaphorisch gemeint ist, dann sind Erfahrungsformen angesprochen, in denen wir unser Verständnis von Wirklichkeit nicht nur reproduzieren, sondern entwickeln, formen, modellieren, konstruieren, transformieren. Das setzt zuerst und vor allem voraus, Wirklichkeit als einen gemeinschaftlich geteilten Horizont je subjektiver Erfahrungsperspektiven überhaupt erst herzustellen. Metaphorisieren ist zuallererst Produktion eines ,Wir‘ der Erfahrung. Das medienwissenschaftliche Erkenntnisinteresse am Verhältnis von metaphorischen Konzepten und audiovisuellen Bewegungsbildern gilt eben der medialen Produktion eines solchen ,Wir des geteilten Erfahrungshorizontes.

Metaphern sind, folgt man Blumenbergs Argumentation, genau in dem Maße von symbolischen Formen ausgebildeter Bedeutungssysteme zu unterscheiden, wie sie sich auf fragwürdige, inkonsistente Positionen geteilter Wirklichkeit beziehen. In der anerkannten symbolischen Form ist das Verhältnis zwischen sprachlichem Ausdruck und Wirklichkeit festgelegt - und damit zugleich ein Stück unstrittiger, gemeinsam geteilter Wirklichkeit fixiert. Metaphorische Konzepte hingegen produzieren einen gemeinschaftlich geteilten Sinn gerade dort, wo etwas als real gelten kann, ${ }^{98}$ obwohl es als selbstverständlich angenommene Wirklichkeit nicht ohne weiteres verfügbar ist.

96 Lakoff/Johnson: Metaphors We Live By, S. 105.

97 Vgl Petra Gehring: Metapher, in: Blumenberg lesen: ein Glossar, hrsg. v. Robert Buch, Daniel Weidner, Berlin 2014, S. 201-213.

98 Noch bevor sie ,eine veränderte Sicht' der Wirklichkeit ermöglichen, muss durch sie überhaupt erst einmal eine geteilte Sicht hergestellt werden. Bestimmte metaphorische Konzepte fungieren also als Instrumente des Denkens, die dazu dienen, einen gemeinschaftlichen Wirklichkeitsbezug auch dort zu sichern, wo dieser nicht selbstverständlich vorausgesetzt werden kann. 


\section{Die rhetorische Verfassung gemeinschaftlich geteilter Wirklichkeit}

Blumenberg hat sein Verständnis von Lebenswelt als Grenzbegriff einer vorreflexiven Existenzform (eines ,fully embodied meaning') entwickelt, gerade um den Bruch in den Blick zu bekommen, der die Reflexivität des menschlichen Denkens begründet. Aus diesem Bruch mit der vorreflexiven Lebenswelt ergibt sich die Notwendigkeit unendlicher „Neu-Beschreibungen“99 einer heterogenen Wirklichkeit. Gemeinschaftlich geteilte Wirklichkeit ist genau in dem Maße rhetorisch verfasst, als sie allgemeingültig sein soll, $d$. h. aus sich selbst heraus verständlich einen Status für sich in Anspruch nimmt, der dem der Wahrheit gleicht.

Deshalb ist für Blumenberg die Metapher der paradigmatische Gegenstand, an dem sich die Funktion der Rhetorik anthropologisch begründen lässt: Rhetorik tritt - so sein Argument - genau dort in Erscheinung, wo keine allgemein geteilte und verbindliche Wahrheit verfügbar ist, die eine geteilte Wirklichkeit verbürgt. Sie zielt darauf ab, einen gemeinschaftlich geteilten Wirklichkeitsbezug, einen common ground dort herzustellen, wo dieser brüchig oder nicht vorhanden ist; ${ }^{100}$ dabei lässt sie immer wieder solche aus sich selbst heraus verständlichen Wirklichkeitsbereiche entstehen, die als Zonen reflexionsfreier Lebensweltlichkeit automatisierten Verstehens, eines ,fully embodied meaning‘, gelten können.

Sinnbildung ist dann per se durch die Verbindung getrennter Subjektivitäten definiert, durch das In-Verbindung-Treten eigensinniger, getrennter KörperBewusstseine in der Medialität des Gestikulierens, Lesens, Sprechens, Bilderrezipierens, Zuhörens und Zuschauens. ${ }^{101}$ Sinn ergäbe sich also keineswegs aus referenziellen Relationen zwischen kognitiven, semiotischen oder linguistischen Systemen und der phänomenalen Wirklichkeit; er wäre vielmehr als eine sich verzweigende dynamische Vernetzung von Affekten, Perzepten und Konzepten $\mathrm{zu}$ verstehen, in die menschliche Akteure, Medien und semiotische Systeme gleichermaßen einbegriffen sind. Sinn entsteht als Effekt eines medial strukturierten Prozesses der Verkörperung - Verkörperung ist darum nicht als konkreti-

99 Vgl. Rorty zum Begriff der Neubeschreibung: Rorty: Der Vorrang der Demokratie vor der Philosophie, S. 100 sowie Richard Rorty: Kontingenz, Ironie und Solidarität, Frankfurt/M. 1989 und Richard Rorty: Achieving Our Country. Leftist Thought in Twentieth-Century America, Cambridge, Mass. 1998.

$100 \mathrm{Vgl}$. Blumenbergs anthropologische Begründung der Rhetorik: „[...] Rhetorik als eine Technik, sich im Provisorium vor allen definitiven Wahrheiten und Moralen zu arrangieren." Blumenberg: Anthropologische Annäherung an die Aktualität der Rhetorik, S. 108-110; das Zitat findet sich auf S. 110 .

101 Sybille Krämer hat diese als die aisthetische Performanz des Phänomenologisierens bezeichnet. Vgl. Krämer: Was haben „Performativität“ und „Medialität“ miteinander zu tun?, S. 21. 
sierender, affizierender oder decodierender Aspekt des Verstehens zu begreifen, sondern bezeichnet letztlich ein Kontinuum von Sinnestätigkeit, Sinnesempfindungen und Sinnverstehen als „Ereignis der prozessualen Gegenwärtigkeit des Medienumgangs“. ${ }^{102}$

Blumenbergs Metaphorologie geht letztlich auf die radikale Umwertung des Wahrheitsbegriffs selbst zurück, der die moderne Philosophie und Wissenschaft recht eigentlich begründet. Mit ihr ist Wahrheit selbst zur Frage der rhetorischen Verfertigung gemeinsam geteilter Wirklichkeitsentwürfe geworden. In Nietzsches „Über Wahrheit und Lüge im außermoralischen Sinne“103 ist diese Umwertung unmittelbar mit der Metapher als Paradigma eines radikalen Perspektivismus verbunden: $:^{104}$

Wir reden von einer Schlange: die Bezeichnung trifft nichts als das Sichwinden, könnte also auch dem Wurme zukommen. Welche willkürlichen Abgrenzungen, welche einseitigen Bevorzugungen bald der bald jener Eigenschaft eines Dinges! Die verschiedenen Sprachen nebeneinander gestellt zeigen, dass es bei den Worten nie auf die Wahrheit, nie auf einen adäquaten Ausdruck ankommt: denn sonst gäbe es nicht so viele Sprachen. Das „Ding an sich“ (das würde eben die reine folgenlose Wahrheit sein) ist auch dem Sprachbildner ganz unfasslich und ganz und gar nicht erstrebenswerth. Er bezeichnet nur die Relationen der Dinge zu den Menschen und nimmt zu deren Ausdrucke die kühnsten Metaphern zu Hülfe. ${ }^{105}$

Die Metapher wird bei Nietzsche zum Inbegriff einer immer nur perspektivisch konstruierten, heterogenen Wirklichkeit, für die kein anderer Wahrheitsgrund anzugeben ist als die menschlichen Formen der Sinnproduktion selbst. Ihre einzige Wahrheit besteht in der Perspektive desjenigen, der darin seine Sicht der Wirklichkeit beschreibt. ${ }^{106}$

Wenn Max Black davon spricht, dass manche Metaphern neue Aspekte unserer Wirklichkeit konstituieren, reformuliert er noch einmal den Gedanken, der aus der Metapher, als bildlicher Ausdrucksweise ohne Wahrheitswert, das rhetorische Instrument zur Erzeugung multiperspektivischer Wirklichkeiten werden ließ:

102 Vgl. Krämer: Sprache - Stimme - Schrift, S. 345.

103 Nietzsche: Über Wahrheit und Lüge im außermoralischen Sinne.

104 Vgl. Kofman: Nietzsche und die Metapher; Andrew Hines: The Revolution of the Status of the Metaphor in Nietzsche's Philosophy. Vortrag gehalten am 4. Juli 2016 auf der RaAM 11, FU Berlin. 105 Nietzsche: Über Wahrheit und Lüge im außermoralischen Sinne, S. 878-879.

106 Vgl. Richard Rorty: Pragmatism, Relativism, Irrationalism, in: ders.: Consequences of Pragmatism. Essays: 1972-1980, Minneapolis 1982, S. 160-175, hier S. 166. 
[...] some metaphors enable us to see aspects of reality that the metaphor's production helps to constitute. But that is no longer surprising if one believes that the "world" is necessarily a world under a certain description - or a world seen from a certain perspective. Some metaphors can create such a perspective. ${ }^{107}$

Bezogen auf die Geschichte menschlicher Erfahrungsformen können bestimmte metaphorische Konzepte neue Realitäten schaffen, die zuvor nicht Teil unserer geteilten Wirklichkeit waren.

\section{CMT und Nietzsches Metapher}

An dieser Stelle wird aber auch deutlich, dass noch die Theorie konzeptueller Metaphern untrennbar mit dem radikalen Perspektivismus Nietzsches verbunden ist. Im Handstreich setzt Metaphors We Live By die Metapher aus den engen Begrenzungen sprachtheoretischer Definitionen frei, mit der diese als geregelte Fehlleistungen innerhalb eines Strukturmodells regulären meaning-makings identifiziert wurden. In dieser Hinsicht vollzieht die CMT mit dem Versuch, die Sprache selbst noch auf kognitive Konstruktionsregeln zurückzuführen - sehr viel radikaler als manche ihrer Kritiker im Feld der Philosophie -, die fundamentale Kehre, die in der Gründungsschrift moderner Metapherntheorie, „Über Wahrheit und Lüge im außermoralischen Sinne“, vorgezeichnet ist.

Thematisiert Nietzsche die Metapher dort doch als Ursprung der menschlichen Sprachen, die noch vor allen Sprachen sich in der Übertragung von Empfindungsreizen in Ausdruckgesten vollzieht:

Ein Nervenreiz zuerst übertragen in ein Bild! Erste Metapher. Das Bild wieder nachgeformt in einem Laut! Zweite Metapher. Und jedesmal vollständiges Ueberspringen der Sphäre, mitten hinein in eine ganz andere und neue. Man kann sich einen Menschen denken, der ganz taub ist und nie eine Empfindung des Tones und der Musik gehabt hat: wie dieser etwa die Chladnischen Klangfiguren im Sande anstaunt, ihre Ursachen im Erzittern der Saite findet und nun darauf schwören wird, jetzt müsse er wissen, was die Menschen den Ton nennen, so geht es uns allen mit der Sprache. Wir glauben etwas von den Dingen selbst

107 Black: More about Metaphor, S. 38. „Aus eben diesen Gründen möchte ich weiter daran festhalten, daß manche Metaphern uns in die Lage versetzen, bestimmte Aspekte der Wirklichkeit zu sehen, zu deren Konstitution die Herstellung der Metapher beiträgt. Das überrascht indessen nicht mehr, wenn man der Ansicht ist, daß die ,Welt‘ notwendig eine Welt in einer bestimmten Beschreibung ist - oder eine Welt, die aus einer bestimmten Perspektive gesehen wird. Manche Metaphern können eine solche Perspektive erzeugen." Black: Mehr über die Metapher, S. 409. 
zu wissen, wenn wir von Bäumen, Farben, Schnee und Blumen reden, und besitzen doch nichts als Metaphern der Dinge, die den ursprünglichen Wesenheiten ganz und gar nicht entsprechen. ${ }^{108}$

Dirk Baecker hat in einem kleinen Essay über Nietzsches Metapherntheorie vorgeführt, dass die Beschreibungssprache Nietzsches in überraschendem Maß mit den gegenwärtigen Modellen der Hirnforschung korreliert. ${ }^{109}$ Tatsächlich lässt sich noch das oben rekonstruierte, neurolinguistische Modell der Wortverarbeitung, der Verzweigung menschlicher Ausdrucksformen im Gebrauch als Werkzeuge kooperierender Interaktionen, unmittelbar auf Nietzsches Ausführung zur Metapher beziehen. Er beschreibt das Affiziert-Sein eines in seinem Sinnesempfinden in die Welt eingelassenen Körpers als - in der Terminologie aktueller Metapherntheorie - die primäre source domain: Ein Körper, dem sein Affiziert-Sein zum Bild seiner situativen Verwicklung wird; und der auf die Affizierung mit einer auf andere Körper gerichteten Ausdrucksgeste (einem Laut) reagiert. Das Intervall der Übertragung eines Affekts in ein Bild des Affiziert-Seins in eine Ausdrucksgeste ist in Nietzsches Perspektive die primäre Form aller metaphorischen Übertragung; aus ihr folgt in der Kette immer weiterer Übertragungen der sprachliche Ausdruck, schlussendlich die Vielheit der Sprachen.

Selbst wenn die spekulativen Argumente Nietzsches für sich keinen Wahrheitsanspruch erheben, beschreiben sie doch sehr präzise in der Umkehr des Verhältnisses von Sprache und Metapher ein menschliches Denken vor der Sprache. Nur ist dessen Beziehung zur Welt durch eine Pluralität subjektiver Standpunkte strukturiert, die ihm wiederum erst in der Vielheit sprachlicher Relationen, erst als Vielheit der Sprachen verfügbar werden. Menschliches Denken bringt die Sprachen in den metaphorischen Übertragungen hervor; aber es kann sich selbst nicht anders denn in der Bildung und Interpretation sprachlicher Relationen begegnen und beschreiben.

In mancherlei Hinsicht kommt die CMT - soweit man die Metapher als „,multidimensional structure [...] of organizing experiences into structured wholes"110 versteht - der Spekulation Nietzsches über den Ursprung der Sprache sehr nahe. Jedenfalls eröffnet die CMT genau soweit einen Zugang zur Sinnbildung filmi-

108 Nietzsche: Über Wahrheit und Lüge im außermoralischen Sinne, S. 879.

109 Vgl. Dirk Baecker: Ein bewegliches Heer von Metaphern. Die Kunst ist die Herkunft. Überlegungen zur Aktualität Friedrich Nietzsches im Jahr seines 100. Todestages, in: der Freitag. Das Meinungsmedium (02. Juni), 2000, https://www.freitag.de/autoren/der-freitag/ein-beweglichesheer-von-metaphern (02. April 2018).

110 Lakoff/Johnson: Metaphors We Live By, S. 81. 
scher Bewegungsbilder, wie sie einen neuen Zugang zum Verständnis der ,kulturellen Entwicklung der menschlichen Sprache‘ begründet; eine Entwicklung, die sich auf die prozessualen Wechselbeziehungen von Wahrnehmungsszenarien (metaphorischer Übertragungen) gründet, die sich im Letzten aus den Formen kooperierender Interaktion herleiten lassen - ohne dass man linguistische oder kognitive Universalien und entsprechende Systeme in Anspruch nehmen muss. ${ }^{111}$

In dieser theoretischen Erweiterung lässt uns die CMT das Netz metaphorischer Bezüge zwischen Affekten, Perzepten und Konzepten als eine dynamische Grundstruktur menschlichen Denkens begreifen, die einem Prozess permanenter Refiguration unterliegt. Mit Nietzsche lässt sich das wie folgt formulieren:

Nur durch das Vergessen jener primitiven Metapherwelt, nur durch das Hart- und Starr-Werden einer ursprünglich in hitziger Flüssigkeit aus dem Urvermögen menschlicher Phantasie hervorströmenden Bildermasse, nur durch den unbesiegbaren Glauben, diese Sonne, dieses Fenster, dieser Tisch sei eine Wahrheit an sich, kurz nur dadurch, dass der Mensch sich als Subjekt und zwar als künstlerisch schaffendes Subjekt vergisst, lebt er mit einiger Ruhe, Sicherheit und Consequenz [...]. ${ }^{112}$

In Nietzsches Perspektive ist das Metaphorisieren die grundlegende Poiesis menschlichen Denkens, deren Produkt die Kultur selber ist. Er versteht sie, zugespitzt formuliert, als Prozess eines permanenten Sprachursprungs, dessen innere Dynamik permanent Wirklichkeiten hervorbringt, verändert und neu figuriert. Sie bezeichnet eine Kraft, die in den Bedeutungssystemen und Wahrheitslehren soweit beherrscht und unter Kontrolle gebracht ist, dass sie sich nur noch theoretisch erschließen lässt.

Bei Blumenberg wird ein vergleichbarer Gedanke greifbar, wenn er schreibt: „Der Grenzwert des Urteils (begriffliche Operation) ist Identität, der Grenzwert der Metapher ist das Symbol.“113 ,Symbol', das meint die allgemein anerkannte Beschreibungsform einer gemeinschaftlich geteilten Wirklichkeit; eine allgemeinverbindliche Ausdrucksform, die regelt und festlegt, was Wirklichkeit ist und was nicht. Die Metapher ist so gesehen immer auf dem Weg zum Symbol - auf dem Weg zur Anerkennung als eine verbindliche Festlegung von Wirklichkeit. (Man könnte auch sagen: auf dem Weg zu einer Konventionalisierung, die sich selbst zu vergessen sucht.)

111 Vgl. Tomasello: Die kulturelle Entwicklung des menschlichen Denkens; Tomasello: Warum wir kooperieren; Goldberg: Constructions; Goldberg: Constructions at Work.

112 Nietzsche: Über Wahrheit und Lüge im außermoralischen Sinne, S. 883.

113 Vgl. Blumenberg: Anthropologische Annäherung an die Aktualität der Rhetorik, S. 120. 
Hier kommt ein weiterer, für die CMT konstitutiver Aspekt zum Tragen; gerade die ,toten' Metaphern nämlich - also jene sprachlichen Wendungen und Ausdrücke, denen man die Übertragung nicht mehr ,anhört' - gelten als Hinweis auf die basale kognitive Funktion metaphorischer Übertragungen, denen sich die Sprachformungen selbst noch verdanken. (Das oben genannte Experiment zur Verarbeitung der Worte ,Greifen“ und ,Begreifen` liefert hier ein schönes Bespiel; steckt doch im ,Greifen' die gleiche metaphorische Übertragung - von einer motorischen Aktion auf eine Lautfolge -, die man im ,Begreifen“ sofort realisiert.)

Anders gesagt: In der Perspektive einer kulturellen Entwicklungsgeschichte des menschlichen Denkens sind noch die Worte Sonne, Fenster, Tisch nichts anderes als allgemein verbindlich gewordene rhetorische Formeln der Wirklichkeitserzeugung. So betrachtet sind auch die vermeintlich ${ }^{114}$ toten Metaphern nur eine Form fragloser Wirklichkeitsbeschreibung, ein Indiz für einen automatisierten Gemeinsinn. In der anerkannten symbolischen Form ist das Verhältnis zwischen sprachlichem Ausdruck und Wirklichkeit festgelegt - und damit ein Stück unstrittiger, gemeinsam geteilter Wirklichkeit entstanden. Was immer auch bedeutet, sie ist zu einer kontrollierten, beherrschten Wirklichkeit geworden.

\section{Historizität und Zeitbewusstsein}

Erst die Situierung der kognitiven Metapherntheorie in der Flucht des modernen Verständnisses von Rhetorik macht es möglich, metaphorische Konzepte auf die Geschichte ihrer „Elaborierung, Transformation und Ausweitung“ in allen Bereichen menschlicher Interaktion $\mathrm{zu}$ beziehen. ${ }^{115}$ In dieser Perspektive mag noch die Geschichte der Poetik und Rhetorik selbst als kulturelle Ausdifferenzierung basaler kognitiver Schemata lesbar sein. ${ }^{116}$

114 Das metaphorische ,Leben` ,toter` Metaphern ist tatsächlich sehr viel ausgeprägter, als es die Rede von ihrem ,Tod‘ vermuten lässt (Vgl. Müller: Metaphors Dead and Alive, Sleeping and Waking).

115 Mark Johnson empfiehlt: „[...] explore more concretely how forceful bodily experiences give rise to image-schematic structures of meaning that can be transformed, extended, and elaborated into domains of meaning that are not strictly tied to the body (such as social interactions, rational argument, and moral deliberation).“ Johnson: The Body in the Mind, S. 44-45.

116 Eine solche historische Poetologie mag der Erforschung der „Poetics of Mind“ (Raymond W. Gibbs: The Poetics of Mind. Figurative Thought, Language, and Understanding, Cambridge 1994) zahllose Hinweise geben und Wege eröffnen. Umgekehrt aber bedeutete der Versuch, diese Geschichte durch kognitive Strukturen erklären zu wollen und den Sinn der kulturellen Produktion in ihrer physiologischen Grundlegung anzugeben, die Mittel als den Zweck zu definieren. 
Sobald man nämlich von Literatur, bildender Kunst oder visueller Medienund Filmkunst spricht, stehen metaphorische Konzepte zur Diskussion, die per definitionem darauf ausgerichtet sind, Wirklichkeit als wandelbaren und prekären gemeinschaftlich geteilten Erfahrungshorizont zu fassen oder auch zu negieren. Deshalb adressieren unsere Fragen zum Verhältnis von metaphorischen Konzepten und filmischem Bewegungsbild das eine wie das andere als Teil einer Geschichte des poetischen Machens gemeinschaftlich geteilter Erfahrungshorizonte. Bezogen auf diese wiederum gilt, dass die Geschichte der von „Menschen geschaffenen Instrumente des Denkens“117 (seien es Metaphern, seien es mediale Displays oder semiotische Systeme), d. i. die Geschichte der Medien des Denkens, der Königsweg zu ihrem Verständnis ist.

Es ist deshalb auch mehr als nur ein anekdotisches Detail, dass die Wahrnehmungsformen filmischer Bilder für Black ein evidentes Beispiel abgeben, an dem eine solche Veränderung unserer Welt durch neue Beschreibungen, neue Perspektiven, greifbar wird..$^{118}$

Er schreibt:

Here the „view“ is necessarily mediated by a man-made instrument (though this might cease to be true if some mutant children were born with the power to see "slow motion“ with one eye). And yet what is seen in a slow-motion film becomes a part of the world once it is seen. ${ }^{119}$

Die Formen unserer Erfahrung wären dann auf nicht weniger vielfältige Weise in diese Geschichte verstrickt wie die Medien, Bedeutungssysteme und Sprachen, in denen wir ihnen Ausdruck verleihen. Genau darauf bezieht sich Black, wenn er der Überzeugung ist: „[...] the ,world“ is necessarily a world under a certain description - or a world seen from a certain perspective. “120

Bezieht man die Überlegung Blacks noch einmal auf die Poiesis des FilmeSehens ${ }^{121}$ lässt sich resümierend Folgendes festhalten: Die Metapher ist als eine Interaktion zu konzipieren, die auf der Ebene sinnlicher Wahrnehmungsszenarien zu verorten ist; eines Sehens und Hörens, das im Abgleich mit den kulturellen Konventionen und Mustern der Alltagswahrnehmung ein fiktionales Szenario entstehen lässt. Das Szenario entsteht im Prozess der Wahrnehmung selbst, der den

117 Vgl. Fußnote 98 dieses dritten Teils.

118 Black: More about Metaphor, S. 37.

119 Black, S. 37.

120 Black, S. 38.

121 Vgl. das zweite Kapitel des ersten Teils dieser Studie. 
„images, patterns, qualities, colors, and perceptual rhythms“122 audiovisueller Bilder - d.h. ihrer Expressivität - eine bedeutungstragende Gestalt verleiht. Metaphern in audiovisuellen Bewegtbildern sind, dem skizzierten Verständnis folgend, dynamische Verknüpfungen unterschiedlicher Erfahrungsbereiche, die im ästhetischen Arrangement filmischer Expressivität als eigenleibliche Erfahrung der Rezipienten konstituiert und zugleich als eigensinniger Erfahrungsmodus einer anderen Subjektivität von deren eigener Subjektivität unterschieden werden.

In diesem Sinne generieren filmische Bilder ein Verstehen und Denken, das sich keineswegs in der Reproduktion bestehender kognitiver Schemata von Bewegung, Raum und Zeit erschöpft, sondern neue Differenzen und Modalitäten in die geteilte Wirklichkeit einführt. Es sind die Medienkonsumenten, die im Akt des Filme-Sehens neue Metaphern, neue Verbindungen zwischen disparaten Erfahrungsdomänen und Erfahrungsperspektiven produzieren, indem sie aus audiovisuellen Bewegtbildern fingierte Wirklichkeiten filmischer Bewegungsbilder entstehen lassen.

122 Johnson: The Meaning of the Body, S. 234. 